\title{
Chained Structure of Dimeric F1-like ATPase in Mycoplasma mobile Gliding Machinery
}

Takuma Toyonaga, Takayuki Kato, Akihiro Kawamoto, Noriyuki

Kodera, Tasuku Hamaguchi, Yuhei O. Tahara, Toshio Ando, Keiichi Namba, Makoto Miyata

\begin{tabular}{|c|c|}
\hline Citation & mBio. 12(4); e01414-21. \\
\hline Published & July/August/2021 \\
\hline Type & Journal Article \\
\hline Textversion & Publisher \\
\hline Highlights & $\begin{array}{l}\text { •最小細菌である「マイコプラズマ・モービレ」の分子モーターの構造を解明。 } \\
\text { •生命に欠かせないATP 合成酵素から進化した全く新しい構造を発見。 } \\
\text { •細胞やタンパク質の進化について新たな理解に繋がる可能性を示唆。 }\end{array}$ \\
\hline $\begin{array}{l}\text { Supplemental } \\
\text { Material }\end{array}$ & Supplemental Material is available at https://doi.org/10.1128/mBio.01414-21 \\
\hline 参考 & $\begin{array}{l}\text { ・動画 : マイコプラズマ・モービレの滑走の様子 } \\
\text { https://www.youtube.com/watch?v=-LRdogB3U8s }\end{array}$ \\
\hline Rights & $\begin{array}{l}\text { (C) } 2021 \text { Toyonaga et al. This is an open-access article distributed under the } \\
\text { terms of the Crestive CommonsAttribution } 4.0 \text { International license. } \\
\text { https://creativecommons.org/licenses/by/4.0/ }\end{array}$ \\
\hline DOI & 10.1128/mBio.01414-21 \\
\hline
\end{tabular}

\section{Self-Archiving by Author(s)}

Placed on: Osaka City University Repository 


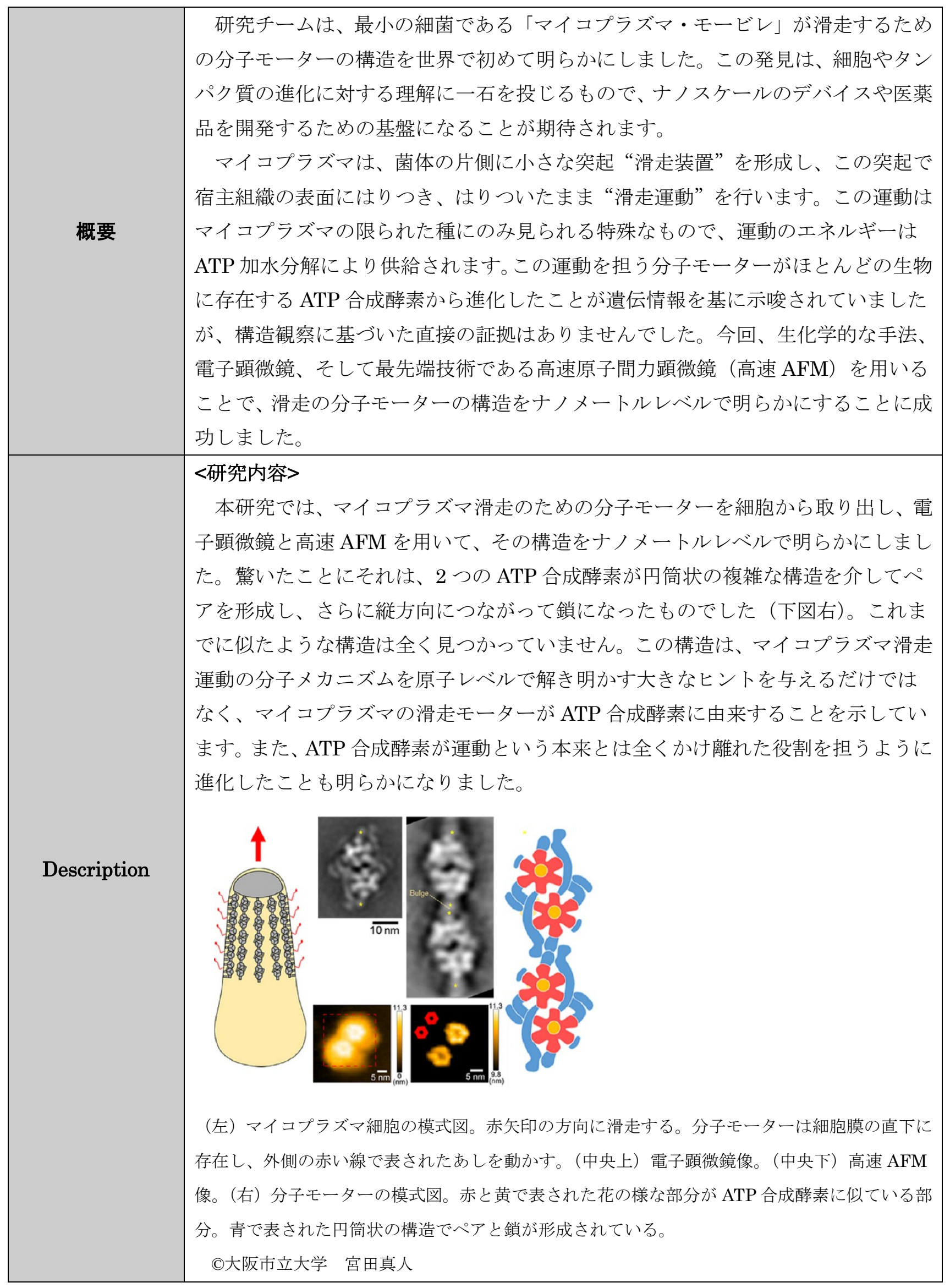

Toyonaga T, Kato T, Kawamoto A, Kodera N, Hamaguchi T, Tahara YO, Ando T, Namba K, Miyata M. 2021. Chained structure of dimeric F1-like ATPase in Mycoplasma mobile gliding machinery. mBio 12: e01414-21. https://doi.org/10.1128/mBio.01414-21. 


\section{$<$ 今後の展開 $>$}

単離した分子モーターをクライオ電子顕微鏡法で解析することで、原子レベルの 構造を明らかにして、ATP 加水分解のエネルギーがどのように滑走運動の動きに変 換されるかを構造から読み解いていきます。また、単離したモーターの ATP 加水 分解反応における実際の動きを高速 AFM により明らかにします。

滑走の構造とメカニズムの詳細を明らかにすることで、運動能の起源と動作原理 に迫ることができ、ナノスケールのデバイスや医薬品を開発するための基盤になる ことが期待されます。

世界初！ATP 合成酵素から変化した滑走のツインモーターの構造を明らかに’。大 阪市立大学. https://www.osaka-cu.ac.jp/ja/news/2021/210720 (参照 2021/07/20) 


\title{
Chained Structure of Dimeric $\mathrm{F}_{1}$-like ATPase in Mycoplasma mobile Gliding Machinery
}

\author{
(D)Takuma Toyonaga, a (D)Takayuki Kato,b (D) Akihiro Kawamoto, (D) Noriyuki Kodera,c (D)Tasuku Hamaguchi, a,d* \\ (D) Yuhei O. Tahara, ${ }^{\text {a,d }}$ (D) Toshio Ando, c (D) Keiichi Namba, e,f,g (1D) Makoto Miyata ${ }^{a, d}$ \\ aGraduate School of Science, Osaka City University, Osaka, Osaka, Japan \\ bInstitute for Protein Research, Osaka University, Suita, Osaka, Japan \\ cNano Life Science Institute (WPI-NanoLSI), Kanazawa University, Kanazawa, Ishikawa, Japan \\ TThe OCU Advanced Research Institute for Natural Science and Technology (OCARINA), Osaka City University, Osaka, Osaka, Japan \\ eGraduate School of Frontier Biosciences, Osaka University, Suita, Osaka, Japan \\ fRIKEN Center for Biosystems Dynamics Research, SPring-8 Center, Suita, Osaka, Japan \\ gJEOL YOKOGUSHI Research Alliance Laboratories, Osaka University, Suita, Osaka, Japan
}

ABSTRACT Mycoplasma mobile, a fish pathogen, exhibits gliding motility using ATP hydrolysis on solid surfaces, including animal cells. The gliding machinery can be divided into surface and internal structures. The internal structure of the motor is composed of 28 so-called "chains" that are each composed of 17 repeating protein units called "particles." These proteins include homologs of the catalytic $\alpha$ and $\beta$ subunits of $F_{1}$-ATPase. In this study, we isolated the particles and determined their structures using negative-staining electron microscopy and high-speed atomic force microscopy. The isolated particles were composed of five proteins, MMOB1660 ( $\alpha$-subunit homolog), -1670 ( $\beta$-subunit homolog), $-1630,-1620$, and -4530 , and showed ATP hydrolyzing activity. The two-dimensional (2D) structure, with dimensions of 35 and $26 \mathrm{~nm}$, showed a dimer of hexameric ring approximately $12 \mathrm{~nm}$ in diameter, resembling $F_{1}$-ATPase catalytic $(\alpha \beta)_{3}$. We isolated the $\mathrm{F}_{1}$-like ATPase unit, which is composed of MMOB1660, -1670 , and -1630 . Furthermore, we isolated the chain and analyzed the three-dimensional (3D) structure, showing that dimers of mushroom-like structures resembling $F_{1^{-}}$ ATPase were connected and aligned along the dimer axis at 31-nm intervals. An atomic model of $\mathrm{F}_{1}$-ATPase catalytic $(\alpha \beta)_{3}$ from Bacillus PS3 was successfully fitted to each hexameric ring of the mushroom-like structure. These results suggest that the motor for $M$. mobile gliding shares an evolutionary origin with $F_{1}$-ATPase. Based on the obtained structure, we propose possible force transmission processes in the gliding mechanism.

IMPORTANCE $F_{1} F_{0}-A T P a s e$, a rotary ATPase, is widespread in the membranes of mitochondria, chloroplasts, and bacteria and converts ATP energy with a proton motive force across the membrane by its physical rotation. Homologous protein complexes play roles in ion and protein transport. Mycoplasma mobile, a pathogenic bacterium, was recently suggested to have a special motility system evolutionarily derived from $\mathrm{F}_{1}$-ATPase. The present study isolated the protein complex from Mycoplasma cells and supported this conclusion by clarifying the detailed structures containing common and novel features as $F_{1}$-ATPase relatives.

KEYWORDS $\mathrm{F}_{1}$-ATPase, rotary motor, parasitic bacteria, electron microscopy, atomic force microscopy, bacterial motility

ycoplasmas are parasitic bacteria characterized by small cell size, a short genome, and lack of a peptidoglycan layer (1-3). Many Mycoplasma species exhibit a unique gliding motility, which is necessary for their infection (4-6). Mycoplasma mobile glides on solid surfaces at 2.0 to $4.5 \mu \mathrm{m} / \mathrm{s}$ in the direction of a protrusion on one side
Citation Toyonaga T, Kato T, Kawamoto A, Kodera N, Hamaguchi T, Tahara YO, Ando T, Namba K, Miyata M. 2021. Chained structure of dimeric $F_{1}$-like ATPase in Mycoplasma mobile gliding machinery. mBio 12:e01414-21. https:// doi.org/10.1128/mBio.01414-21.

Editor Lotte Sogaard-Andersen, Max Planck Institute for Terrestrial Microbiology

Copyright $\odot 2021$ Toyonaga et al. This is an open-access article distributed under the terms of the Creative Commons Attribution 4.0 International license.

Address correspondence to Makoto Miyata, miyata@osaka-cu.ac.jp.

* Present address: Tasuku Hamaguchi, Biostructural Mechanism Laboratory, RIKEN SPring-8 Center, Sayo, Hyogo, Japan.

Received 20 May 2021

Accepted 14 June 2021

Published 20 July 202 
A

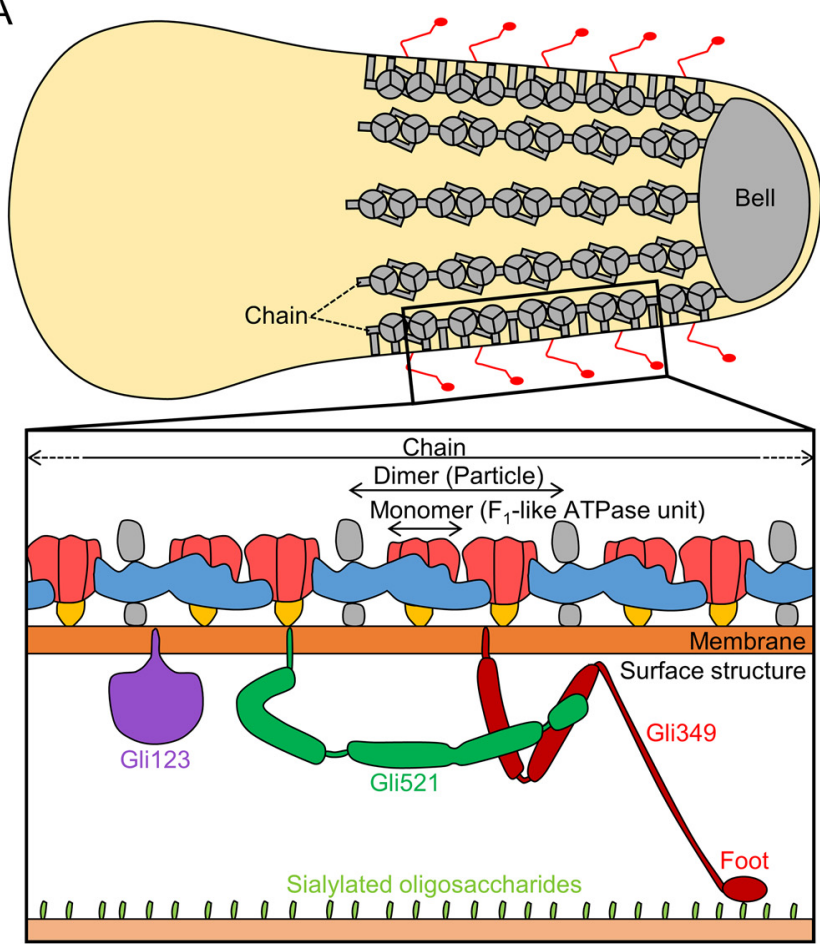

В ммов

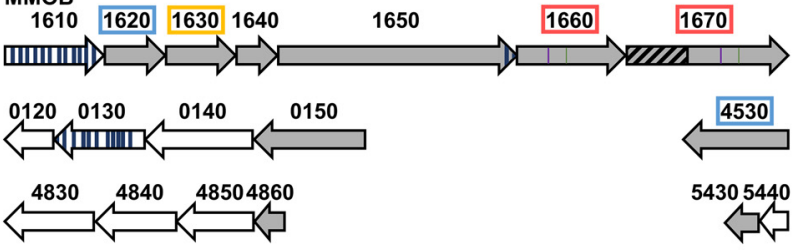

$\Rightarrow$ Component ITransmembrane segment IWalker A motif (P-loop)

I Walker B motif $\square$ Extra $\mathrm{N}$-terminal region

FIG 1 Gliding machinery of Mycoplasma mobile. (A) Schematic illustration of gliding machinery based on the present study. In the whole cell shown at the top, the internal structure and legs are colored gray and red, respectively. The actual cell has approximately 28 chains, each consisting of 17 particles and connecting to bell, although a more limited number is illustrated here. In this paper, we refer to the particle and $F_{1}$-like ATPase unit as the "dimer" and the "monomer," respectively. A single unit of the surface structure and a chain of the internal structure are magnified at the bottom. (B) Open reading frames (ORFs) for the internal structure. The components of the internal structure are colored gray. Type 2 ATPase operon is at the top. Dimer components revealed in the present study are marked by colored boxes, corresponding to the colored components of the bottom illustration in panel A.

of the cell (see Fig. S1 in the supplemental material) (5). The gliding machinery is localized to the cell protrusion and can be divided into surface and internal structures (Fig. 1A, top). The surface structure has approximately 450 repeats of a complex of three large proteins, Gli123, Gli521, and Gli349, inserted into the cell membrane (Fig. 1A, bottom) (7-11). Fifty-nanometer-long leg structures corresponding to Gli349 molecules can be seen jutting out from the cell protrusion by electron microscopy (EM) (12). The tip of Gli349 is characterized by a "foot" with an oval structure that can bind to sialylated oligosaccharides (SOs) (13-20). Gli521 and Gli123 serve as the "crank" that transfers force to Gli349 and the "mount" that localizes the other two surface proteins to the gliding machinery, respectively. A working model of the gliding mechanism has been proposed in which the cells are propelled by Gli349 molecules that repeatedly catch, pull, and release SOs on solid surfaces $(5,21-23)$.

The internal structure consists of a lumpy structure called a "bell" at the tip of the cell protrusion and 28 "chains" lining the inner membrane surface (Fig. 1A) (23-26). 
Each chain is characterized by 17 repeating particle structures, resulting in a total of 476 particles in one cell. The chains tend to form sheets when they are isolated from cells, suggesting lateral interaction with the adjacent chains $(23,24)$. The internal structure consists of least 10 proteins (Fig. 1B). Six of these proteins, MMOB1620, -1630, $-1640,-1650,-1660$, and -1670 were coded tandemly in a locus. Interestingly, MMOB1670 and -1660, which have Walker A and B motifs that are involved in ATP binding and hydrolysis (27), show high amino acid sequence identity with the catalytic $\beta$ and non-catalytic $\alpha$ subunits of $\mathrm{F}_{1}$-ATPase, respectively. MMOB1670 has an extra Nterminal region (amino acids 1 to 299), which is not present in the $\beta$ subunit. The chains most likely contain the motor for gliding, because the gliding motility is coupled to ATP hydrolysis $(23,28,29)$.

$F_{1} F_{0}$-ATPases, found in most organisms, are rotary motors that perform biological energy conversion $(30,31)$. Their role is both to synthesize ATP using a proton motive force and, conversely, to hydrolyze ATP to drive protons to maintain the membrane potential. Their structure is composed of a soluble catalytic $F_{1}$ domain for ATP catalysis and a membrane-embedded $F_{o}$ domain for the proton pathway. In the $F_{1}$ domain, the catalytic $\beta$ and non-catalitic $\alpha$ subunits alternate to form the hexameric ring $(\alpha \beta)_{3}$ that rotates the central stalk penetrating the ring using ATP hydrolysis. Phylogenetic studies have shown that Mycoplasma cells have three $\mathrm{F}_{1}$-like ATPase clusters, which are referred to as type 1 to 3 ATPases $(26,32)$. Type 1 , found in all mycoplasmas, is a typical operon encoding $F_{1} F_{0}$-ATPase and is likely to function as a proton pump to maintain membrane potential. Type 3 is found in mycoplasmas that have an MIB-MIP system to cleave host immunoglobulins (33). Type 2 is only found in four Mycoplasma species, including M. mobile. Interestingly, the type 2 ATPase of M. mobile, which comprises MMOB1620 to -1670 , is involved in the internal structure of the gliding machinery.

Recently, the chains of the internal structure were shown to have structural changes linked to ATP hydrolysis. However, it is still unclear how the chain generates and transmits the force to the outside, because its detailed structure has not been clarified. In this study, we isolated the chains and elucidated their structures. The structure had a common architecture with $\mathrm{F}_{1}$-ATPase, suggesting that the chain shares a common evolutionary origin with $\mathrm{F}_{1}$-ATPase. Based on our findings, we suggest two possible force transmission models for the gliding machinery.

\section{RESULTS}

Isolation and biochemical analyses of a stable unit complex. In this study, we isolated and analyzed three fractions, including "dimer," "monomer," and "chain" structures, which are schematically shown in Fig. 1A (see also Fig. S2 and S3 in the supplemental material).

First, to isolate a stable unit complex from the chain, we lysed cultured M. mobile cells with $1 \%$ Triton X-100 and recovered the insoluble fraction by centrifugation (24). This fraction, named pellet-1, was used for further preparations. We suspended pellet-1 in suspension buffer, which contained $137 \mathrm{mM} \mathrm{NaCl}$, and solubilized the putative unit complex for $8 \mathrm{~h}$. Here, we used $137 \mathrm{mM} \mathrm{NaCl}$ rather than $400 \mathrm{mM}$ to reduce the contamination of other proteins. The soluble fraction was then subjected to Superdex 200 gel filtration chromatography. The obtained peak fraction in the void contained MMOB1620, $-1630,-1660$, and -1670 , which are coded for in the mycoplasma type 2 ATPase operon, and MMOB4530, annotated as phosphoglycerate kinase (PGK) (Fig. 2A). These proteins are known to be components of the internal structure (Fig. 1B) (23-26).

To examine the assembly of these proteins, we applied the isolated fraction to gel filtration chromatography using a Sephacryl S-400 HR column, which can fractionate up to $8,000-\mathrm{kDa}$ globular proteins (Fig. 2B). The proteins eluted as a single peak at a nonvoid position and were larger than $669 \mathrm{kDa}$, suggesting that they form a large complex. The molar ratios of the components were estimated to be 3.2:2.9:3.0:1.0:2.3 for MMOB1670, $-4530,-1660,-1630$, and -1620 , respectively, from the relative intensity of 

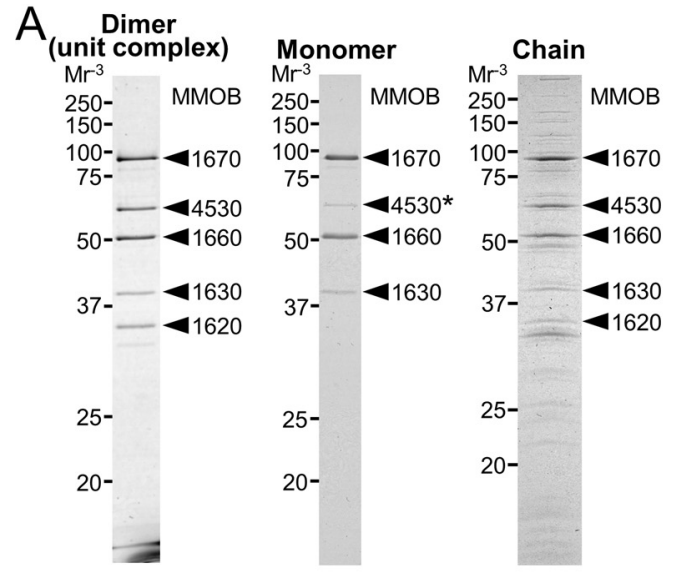

B
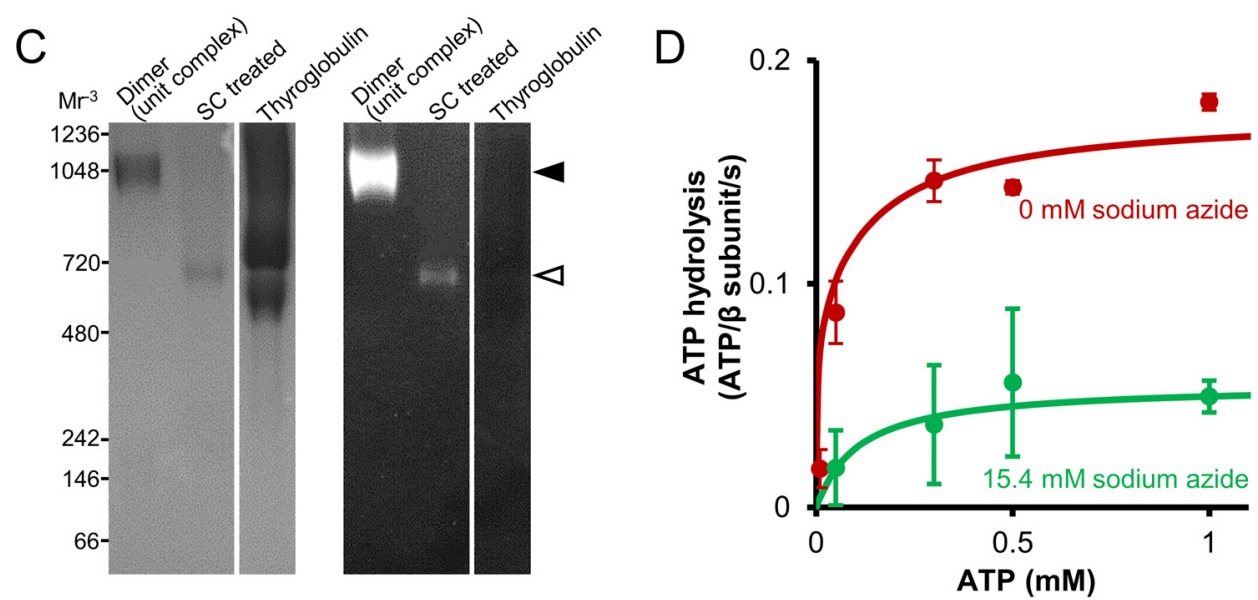

FIG 2 Protein profile and characterization of three fractions. (A) Protein profile of each fraction. Dimer, monomer, and chain fractions were subjected to SDS-12.5\% PAGE gel and stained with CBB. The bands marked by black triangles were identified by peptide mass fingerprinting (PMF). The intensity of the band marked by an asterisk is reduced in the monomer fraction. Molecular masses are shown on the left. (B) Gel filtration assay of unit complex fraction using Sephacryl S-400 HR column. The peak positions of unit complex (dimer) and thyroglobulin $(669 \mathrm{kDa})$ are marked by orange and purple triangles, respectively. (C) BN-PAGE (left) and in-gel ATPase activity assay (right). Dimer, dimer treated with 1.5\% sodium cholate (SC treated), and thyroglobulin, which has no ATPase activity, were subjected to $3 \%$ to $12 \%$ gradient BN-PAGE. The bands of the dimer and monomer after sodium cholate treatment are marked by closed and open triangles, respectively. White lead phosphate bands, indicating ATPase activity, appeared in the panel on the right. Molecular masses are shown on the left. (D) Phosphate release assay of the dimer under various ATP concentrations with and without sodium azide. The ATPase activities under 0 and $15.4 \mathrm{mM}$ sodium azide are marked by red and green filled circles, respectively $(n=3)$. These data were fitted by the Michaelis-Menten equation as solid lines.

the SDS-PAGE bands. We then analyzed the isolated fraction by blue-native (BN) PAGE (Fig. 2C, left). A single band was detected, which is consistent with the result of gel filtration chromatography showing a single peak. Next, we applied the band to an in-gel ATPase activity assay, which detects the activity as a white precipitation of lead caused by the release of inorganic phosphate (Fig. $2 \mathrm{C}$, right). The band with the complex showed precipitation, whereas the band with thyroglobulin, the negative control, did not. This result indicates that the isolated complex has ATPase activity.

In addition, we assayed the isolated fraction for phosphate release from solution. The complex hydrolyzed ATP at a maximum turnover rate of 0.18 molecules/s per MMOB1670 subunit, $\beta$-subunit homolog, with a $K_{m}$ of $74 \mu \mathrm{M}$ at $25^{\circ} \mathrm{C}$ (Fig. 2D). The ATPase activity was inhibited by addition of $15.4 \mathrm{mM}$ sodium azide, an inhibitor of ATPases with Walker A motifs (34), with a $K_{m}$ of $108 \mu \mathrm{M}$ and a maximum turnover rate of 0.055 molecules/s. In a previous study, the Triton-insoluble fraction, which included the internal structure, showed ATPase activity with a $K_{m}$ of $66 \mu \mathrm{M}$ and a maximum turnover rate of 0.09 molecules/s and was suppressed by $15.4 \mathrm{mM}$ sodium azide, 
showing a $K_{m}$ of $84 \mu \mathrm{M}$ and a maximum rate of 0.063 molecules/s (23). The values obtained here are comparable to these previous data. The above-described results suggest that the isolated complex is the motor in the internal structure of the gliding machinery. We used this unit complex for further analyses.

Hexamers resembling $F_{1}$-ATPase catalytic $(\boldsymbol{\alpha} \boldsymbol{\beta})_{3}$ form a dimer. We observed the unit complex by EM using the negative-staining method. A field image showed uniform particles with dimensions of 40 and $20 \mathrm{~nm}$ (Fig. 3A and B). As the particle frequency depended on the protein concentration, we concluded that the observed particles were a part of the protein complex. We picked 2,148 particle images automatically using RELION software (35) for two-dimensional (2D) classification. From the 2D classification, we obtained four clear particle images (see Fig. S4). We adopted mirror images according to the structure observed in high-speed atomic force microscopy (HS-AFM) (see below). Structural handedness cannot be judged from EM images because they are projections of electrons transmitted through the sample. We focused on an image showing a complex structure with dimensions of 35 and $26 \mathrm{~nm}$ featuring nearly 2-fold symmetry (Fig. $3 C$ and D). Interestingly, the characteristic hexamer of approximately $12 \mathrm{~nm}$ in diameter formed a dimer and was reminiscent of $F_{1}$-ATPase catalytic $(\alpha \beta)_{3}$. Considering that the amino acid sequences of MMOB1660 and -1670 have high identity to the $\alpha$ and $\beta$ subunits of $\mathrm{F}_{1}$-ATPase, respectively, the dimeric complex is likely an evolutionary related $F_{1}$-ATPase. The distance between the centers of the two hexamers was $11.0 \mathrm{~nm}$. The complex had 10 filamentous structures around the two hexamers, four of which appeared to form bridges across the two hexamers. The filamentous structures are unlikely artifact, because they showed common features in four independent averaged images (Fig. S4). Here, we refer to this structural unit as a "dimer."

The hexamer featured a ring and a peak in HS-AFM of a dimer. Next, we visualized the dimer using HS-AFM to clarify the structure under liquid conditions, because the molecules are under a dry condition under negative-staining EM. HS-AFM is a powerful method that can visualize the structure and dynamics of single molecules under liquid conditions at a video rate $(36,37)$. In this method, a specimen is placed on the stage surface and, with a probe, is scanned in buffer at high speed. In this study, we placed a dimer on a mica surface and scanned it in an area of 70 by $70 \mathrm{~nm}^{2}$ at 56 by 56 pixels with a scanning rate of 100 ms per frame. HS-AFM images showed a complex with dimensions of approximately 30 and $20 \mathrm{~nm}$ composed of two globules and attached by 2 to 4 lateral protrusions shorter than $15 \mathrm{~nm}$ (Fig. 3E; see also Movie S1 and S2). The dimer images were categorized into two patterns as either a ring (pattern I) or a peak (pattern II), based on the central part. Then, we observed them at a higher resolution (area, 40 by $40 \mathrm{~nm}^{2}$ with 50 by 50 pixels; scanning rate, $100 \mathrm{~ms}$ per frame) (Fig. 3F). In pattern I, the slice image near the top end of the particle between 9.8 and $11.3 \mathrm{~nm}$ above the substrate surface showed two hexameric rings (Fig. 3G). The position and direction of the two rings are consistent with those of the hexamers in the negative-staining EM image. In addition, the distance between the centers of the two hexameric rings was $10.4 \mathrm{~nm}(\mathrm{Fig} .3 \mathrm{H})$, similar to the distance between the centers of the hexamers in the negative-staining EM image (Fig. $3 C$ ). These observations suggest that the shape of the dimer structure in liquid is preserved under negative-staining EM conditions and that the hexamers form rings like $\mathrm{F}_{1}$-ATPase catalytic $(\alpha \beta)_{3}$. In pattern II, the two central peaks were positioned $11.2 \mathrm{~nm}$ apart (Fig. $3 \mathrm{H}$, bottom), similar to the distance between the centers of the hexameric rings in pattern I (Fig. $3 \mathrm{H}$, top), suggesting that patterns I and II are two sides of the same coin (Fig. 3E, left). The distances between the hexameric rings are slightly different for patterns I and II, at 10.4 and $11.2 \mathrm{~nm}$, respectively. This difference suggests that the central axes of two hexamers are not parallel. Considering that HS-AFM detects surface structures while EM shows projection images, the corresponding distance, $11.0 \mathrm{~mm}$, in EM is consistent with the numbers obtained from HS-AFM. Interestingly, in most of the particles, the two peaks at 6 and $5 \mathrm{~nm}$ became invisible in $20 \mathrm{~s}$, between frames 1 and 3 (Fig. $3 \mathrm{l}$ and J; Movie S3). We concluded that these subunits dropped out from the complex, because they 
A

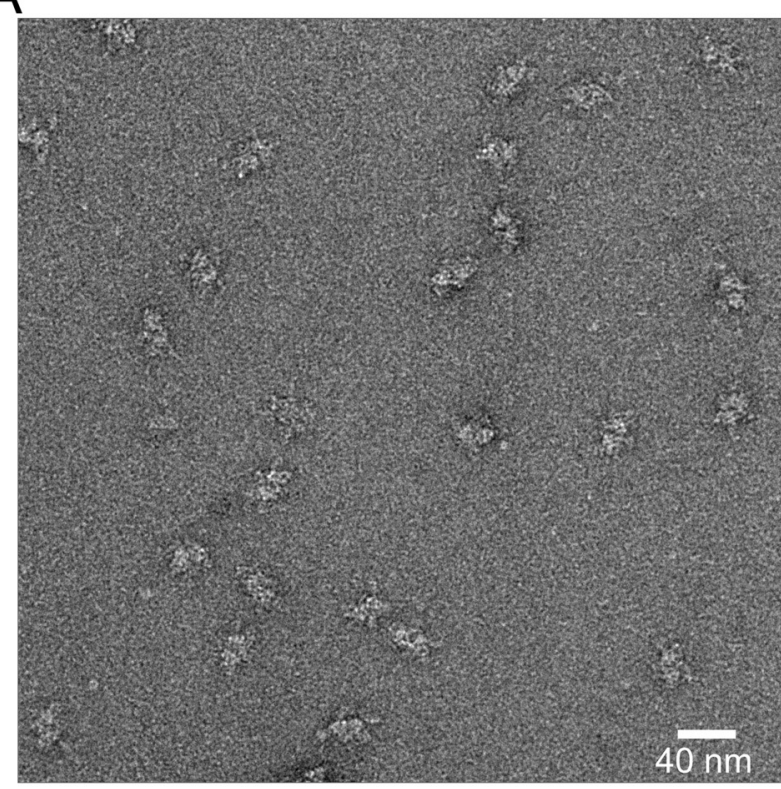

B

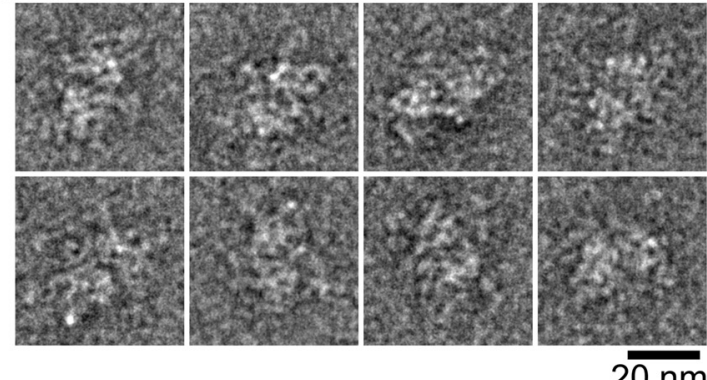

C

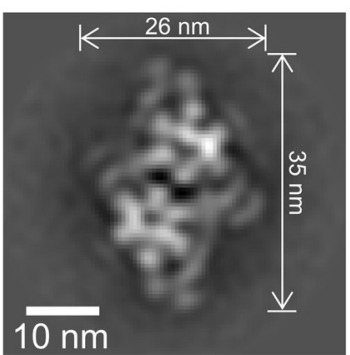

D

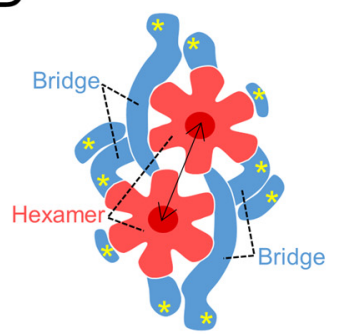

E
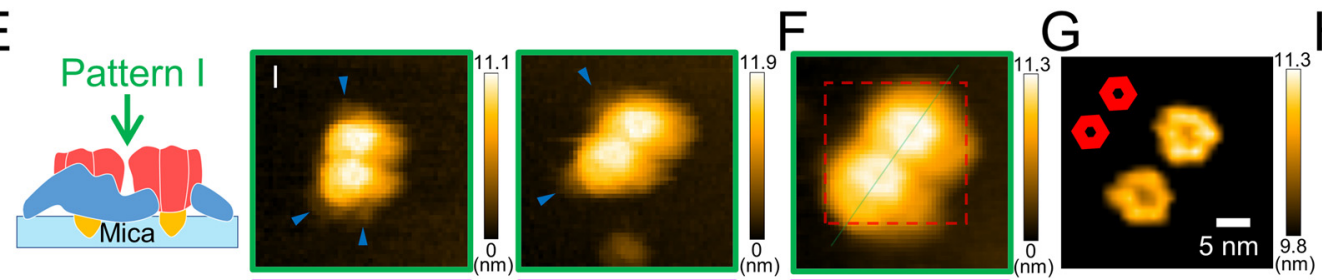

$\mathrm{H}$
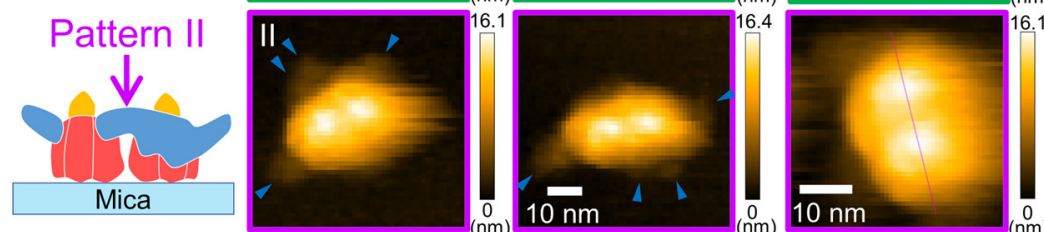

I
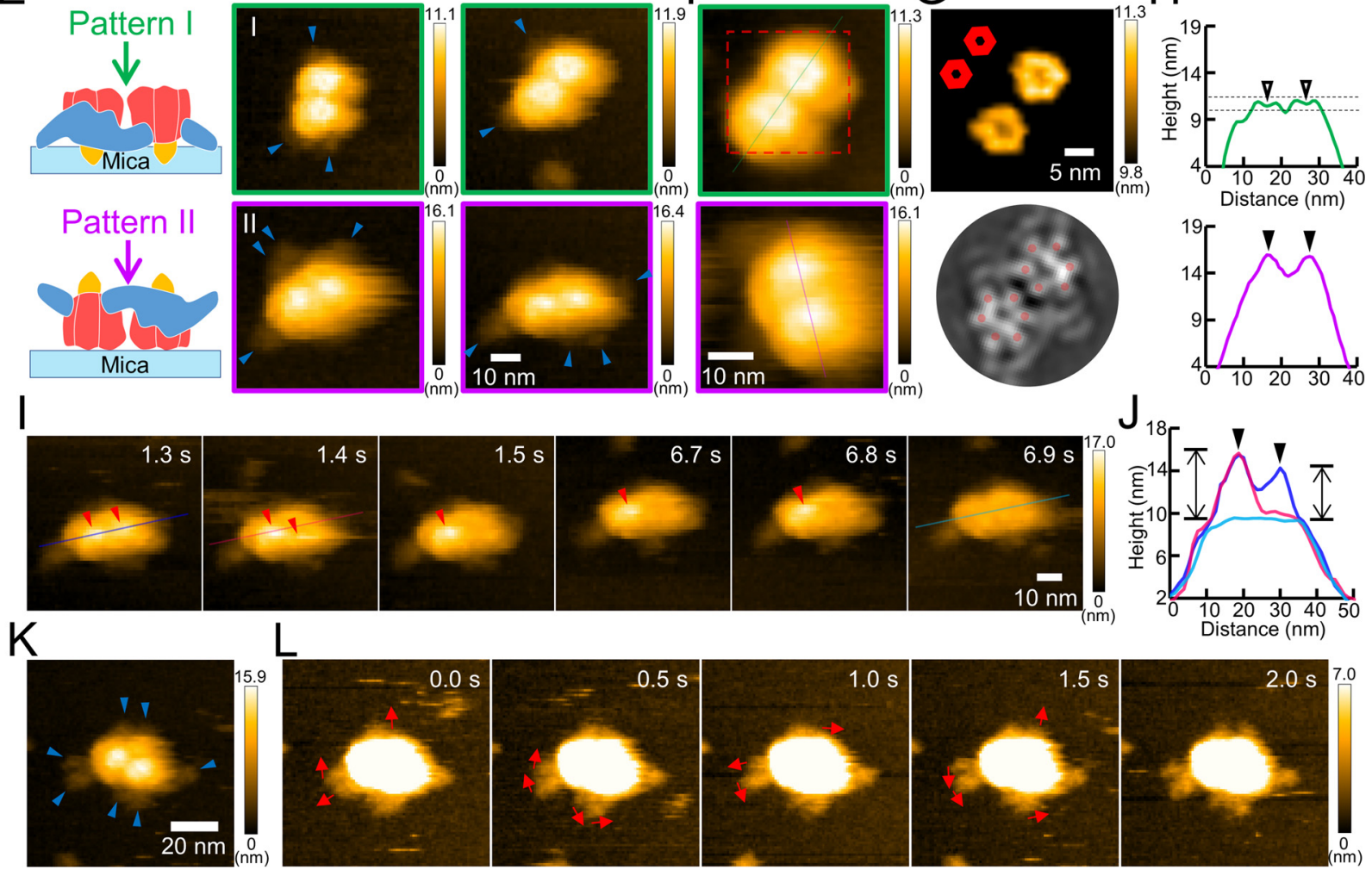

FIG 3 Negative-staining EM and HS-AFM of dimer. (A) Electron micrograph of negatively stained particles in unit complex fraction. (B) Images of individual particles. (C) Representative 2D averaged image. A mirror image is shown to match the orientation of the hexameric ring observed by HS-AFM. (D) Illustration based on the averaged image in panel C. Filamentous structures are marked by asterisks at the ends. The double-headed arrow shows the distance between the centers of the hexamers. (E) Two patterns of HS-AFM images. A dimer was scanned at 56 by 56 pixels in an area of 70 by $70 \mathrm{~nm}^{2}$ with a scanning rate of $100 \mathrm{~ms}$ per frame. Illustrations for patterns I and II (left) were depicted based on 3D chain model shown in Fig. 5. Observation directions are indicated by arrows. Lateral protrusions are marked by blue triangles. Images of patterns I and II are shown in green and purple frames, respectively. (F) Averaged images for patterns I (green frame) and II (purple frame). Dimer was scanned at 50 by 50 pixels in an area of 40 by $40 \mathrm{~nm}^{2}$ with a scanning rate of $100 \mathrm{~ms}$ per frame. The images were produced by averaging three successive video frames. (G) HS-AFM slice image showing two hexameric rings (top) and averaged EM image (bottom). (Top) The red broken boxed area in panel $F$ was sliced for the height 9.8 to $11.3 \mathrm{~nm}$ from the substrate surface, processed for smoothing, and magnified. The angle alignments of two hexamers are schematically shown at the top left. (Bottom) The central part of panel $\mathrm{C}$ was excised and aligned to compare with the top panel. Subunits of the hexamer are marked by red circles. $(\mathrm{H})$

(Continued on next page) 
A

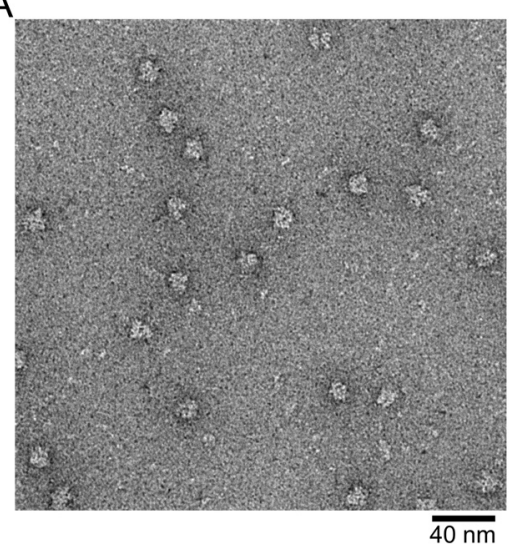

B

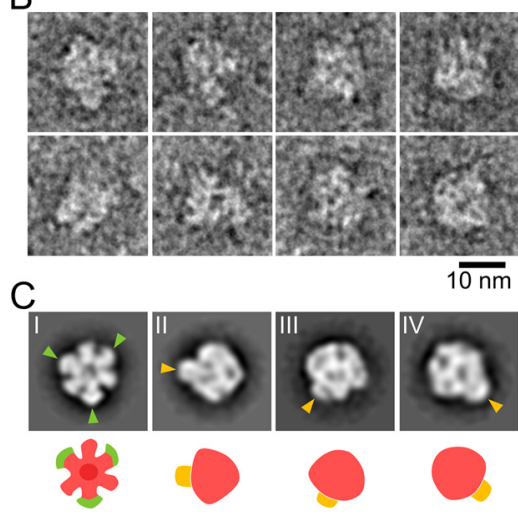

FIG 4 Negative-staining EM of the monomer fraction. (A) Electron micrograph of negatively stained ATPase in a monomer fraction. (B) Images of individual particles. (C) Representative 2D averaged images (top) and depictions of their structures (bottom). (Top) Hook structures in the hexameric ring and the stalks are marked by green and orange triangles, respectively. (Bottom) The hexameric part, hook structures and the stalk are colored rose, green, and orange, respectively.

did not reappear before the complex was disrupted. Next, we focused on the lateral protrusions of these particles, which may be related to the sheet formation of chains (23). To visualize them more clearly, we scanned a dimer by HS-AFM with an area of 120 by $120 \mathrm{~nm}^{2}, 120$ by 120 pixels, and a scanning rate of $500 \mathrm{~ms}$ per frame. The dimer showed seven lateral protrusions around the two globules (Fig. 3K). These protrusions swayed without being fixed (Fig. 3L; Movie S4).

Isolation and structure of a monomer. To clarify the components and structure of the hexamer, we focused on the monomeric hexamer, called a monomer (Fig. S2). We treated the dimer fraction with $1.5 \%$ sodium cholate, an anionic detergent. BN-PAGE and in-gel ATPase activity assays showed a single band with ATPase activity at a position lower than the original one, corresponding to 720 to $1,048 \mathrm{kDa}$, indicating that the dimer dissociated into smaller units with ATPase activity (Fig. 2C, left). Therefore, to isolate a monomer, we applied pellet- 1 sequentially to treatments with $250 \mathrm{mM} \mathrm{NaCl}$ for $8 \mathrm{~h}$ and $1.5 \%$ sodium cholate for $7 \mathrm{~h}$ and to Sephacryl S-400HR gel filtration chromatography (Fig. S2). The elution pattern showed a rather isolated small peak following overlapping peaks (Fig. S3C). An SDS-PAGE gel showed that MMOB1670, -1660, and -1630 eluted in the same fractions, while MMOB4530 and -1620 eluted at later fractions (Fig. S3C and D), indicating that MMOB4530 and -1620 dissociated from the dimer by sodium cholate treatment. Then, we focused on the small peak fraction, which mainly contained MMOB1670, -1660, and -1630 (Fig. 2A, middle; Fig. S3D). This complex presumably corresponds to the BN-PAGE band showing ATPase activity (Fig. 2C, right), because only MMOB1660 and -1670 have the Walker A and Walker B motifs in the dimer components. EM observation using the negative-staining method showed uniform globular particles 10 to $15 \mathrm{~nm}$ in diameter (Fig. $4 \mathrm{~A}$ and B). As the particle frequency depended on the protein concentration, we concluded that the observed particles were a part of a monomer. We picked 11,687 particle images automatically using

FIG 3 Legend (Continued)

Surface profiles along the lines in pattern I (green) and II (purple). The top and bottom images in panel F were each profiled at the green and purple lines passing the globule centers. The dimples and the peaks are marked by open and black triangles, respectively. The slice height in panel $\mathrm{G}$ is shown by broken lines. (I) Shedding process of the peaks of pattern II particle shown in panel E. The peaks are marked by red triangles. (J) Surface profile showing the disappeared peaks. The images in panel I were each profiled at the blue, pink, and light blue lines passing the globule centers. The peaks are marked by black triangles. The double-headed arrows show the peak heights. (K) HS-AFM image of a dimer with seven lateral protrusions. Dimer was scanned at 120 by 120 pixels in an area of 120 by $120 \mathrm{~nm}^{2}$ with a scanning rate of $500 \mathrm{~ms}$ per frame. Lateral protrusions are indicated by blue triangles. (L) Fluctuations of the protrusions of the particle shown in panel K. The images were sliced for the height 0 to $7.0 \mathrm{~nm}$ from the substrate surface. The moving directions are indicated by arrows. In all HS-AFM images, the color bar on the right shows the range of image heights. 
RELION software for 2D classification. By 2D classifying the images into 50 classes, we obtained 15 clear particle images, which were averaged (see Fig. S5). Fig. 4C shows a 12-nm-diameter globule characterized by a single hexameric ring, corresponding to a part of the dimer image in Fig. 3C. Three of the subunits were larger than the others, with hook structures on either side of the edge. Three averaged images (II to IV) showed a mushroom-like structure resembling $F_{1}$-ATPase, which is characterized by a 12-nm-diameter umbrella and a 3-nm-long stalk (Fig. 4C). Now, we can suggest that MMOB1670, -1660, and -1630 form a monomer, i.e., an $F_{1}$-like ATPase unit. MMOB4530 was probably not included in this unit because it probably binds to the complex and could not be distinguished in the image due to the low proportion of bound entities (Fig. 2A, middle). Thus, the hexameric ring is likely formed by the $\alpha$-subunit homolog MMOB1660 and the $\beta$-subunit homolog MMOB1670, and the stalk is formed by MMOB1630.

Isolation and structure of a chain. In gliding machinery, dimers link to form chains. To characterize these chains, we isolated a "chain fraction" with milder mechanical treatment than those for other fractions. Pellet- 1 was treated with $387 \mathrm{mM} \mathrm{NaCl}$, and the soluble fraction was isolated. The chain fraction contained more than 30 proteins, including the dimer component proteins MMOB1670, $-4530,-1660,-1630$, and -1620 as major components (Fig. 2A, right). EM observation using the negative-staining method showed chain structures with lengths longer than $70 \mathrm{~nm}$ and particles of various sizes (Fig. 5A and B). This time, we manually picked 2,127 particles from the chain images, overlapping approximately $50 \%$ of the $71-$ by $71-\mathrm{nm}^{2}$ box area. From 2D classifcation, we obtained seven clear particle images (Fig. 5C). The particle images show the various orientations required for three-dimensional (3D) reconstruction. We then created a 3D map by combining a total of 1,709 particle images of good quality (Fig. 5D and Fig. S6). The 3D map with dimensions of 70,20 , and $15 \mathrm{~nm}$ at a density threshold (contour level $=0.026$ ) was composed of two dimers of mushroom-like structures resembling $F_{1}$-ATPase, aligned along the dimer axis (Fig. 5D). Dimers were connected by a bulge structure with a diameter of $5 \mathrm{~nm}$. The chain interval was $31 \mathrm{~nm}$, consistent with the corresponding dimension in a 2D image from electron cryotomography (ECT) (23), suggesting that the 3D model obtained reflects the original structure from a cell. The mushroom-like structure with a diameter of $15 \mathrm{~nm}$, consisting of a hexameric ring and a central stalk, was connected to the dimer by two bridge structures with a diameter of 3 to $6 \mathrm{~nm}$. An atomic model of $\mathrm{F}_{1}$-ATPase catalytic $(\alpha \beta)_{3}$ from Bacillus PS3 (PDB identifier [ID] 6N2Y) (38) was fitted into each hexameric ring of the mushroom-like structure (Fig. 5E). The distance between the centers of the fitted $(\alpha \beta)_{3}$ in the dimer was $12.5 \mathrm{~nm}$, which is consistent with that of the dimer observed by negative-staining $\mathrm{EM}$ and HS-AFM (Fig. $3 \mathrm{C}$ and $\mathrm{H}$ ). The fitted model showed that each hexameric ring had two protrusions of 3 to $6 \mathrm{~nm}$ pointing laterally (Fig. 5E). The cross sections of each mushroom-like structure showed a central stalk length of $5 \mathrm{~nm}$ (Fig. 5F). A cavity was observed at the center of the hexameric ring. However, it may be an artifact of the low-resolution map of negative-staining EM, because metal coating tends to emphasize the peripheral part of large particles (39). Next, we compared a reprojection image of the 3D chain map with the 2D averaged image of the dimer from negative-staining EM in corresponding handedness (Fig. 5G). Two short filaments marked by asterisks in the dimer (Fig. 5G, left) were positioned facing each other in the connecting bulge (Fig. 5G). Previously, ECT of a permeabilized M. mobile cell showed a chain structure characterized by repeats of two globules and two types of projections to the cell membrane (Fig. 5H, left) (23). The hexameric ring and the central stalk in the 3D map here correspond to the globule and one type of projection to the cell membrane in the ECT image, respectively, suggesting that the chain is oriented with the central stalk facing the membrane, which is common in $\mathrm{F}_{1}$-ATPases. At the interface between dimers, the 3D map here did not include a structure composed of another type of projection and a globule as observed in the ECT image. The subunits corresponding to these structures probably had structural variations or dissociation during the isolation process. 
A

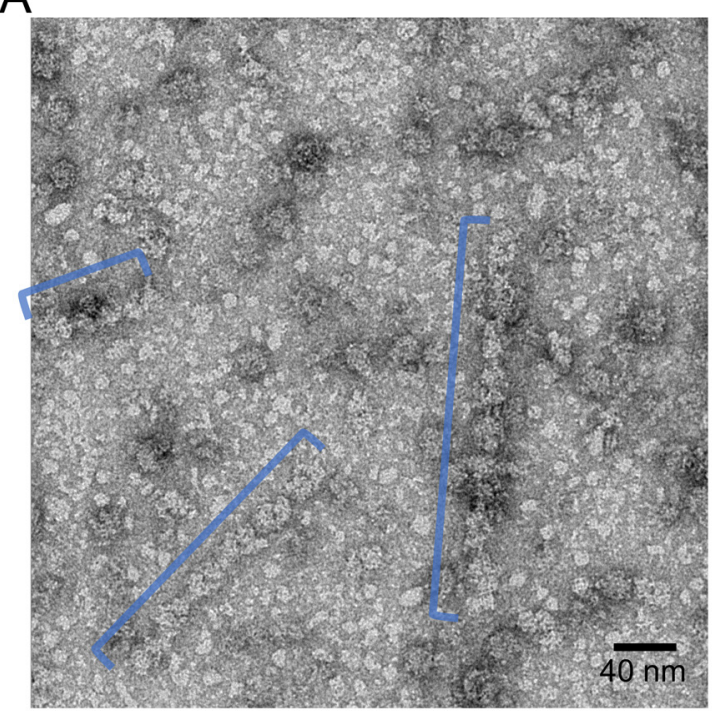

B

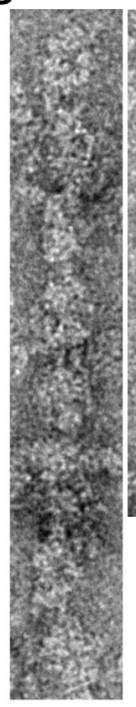

C

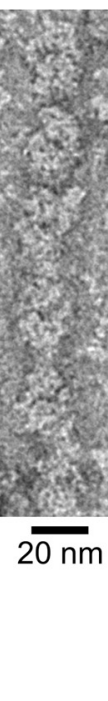

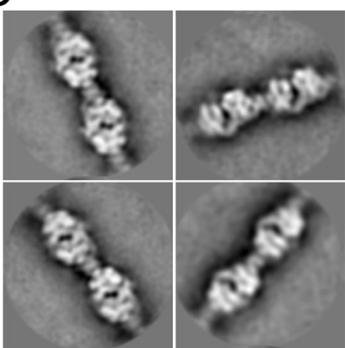
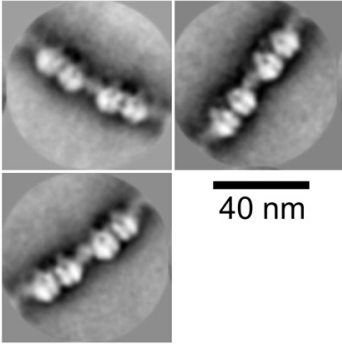

$40 \mathrm{~nm}$
D

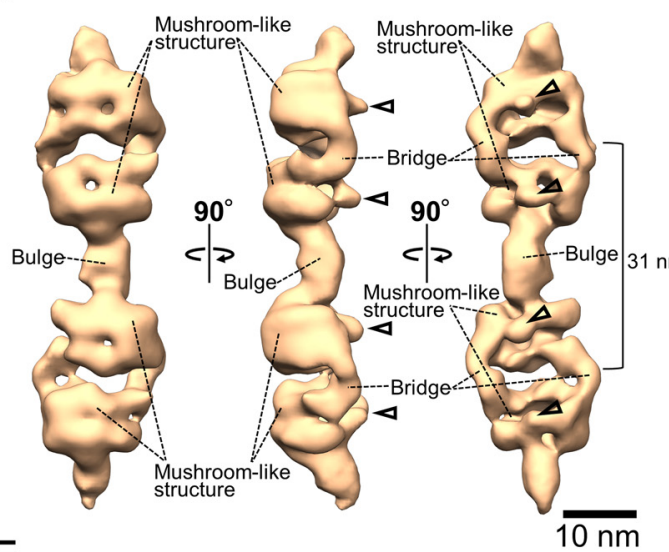

E

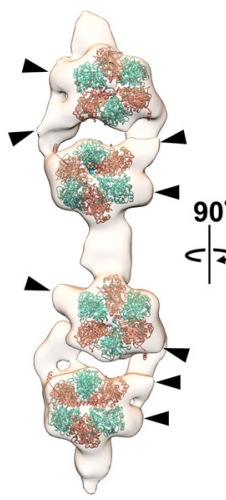

$\mathrm{F}$

(a)

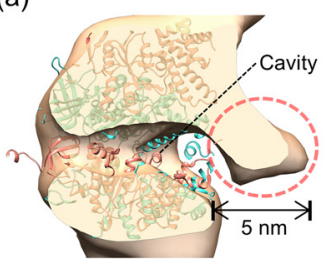

G
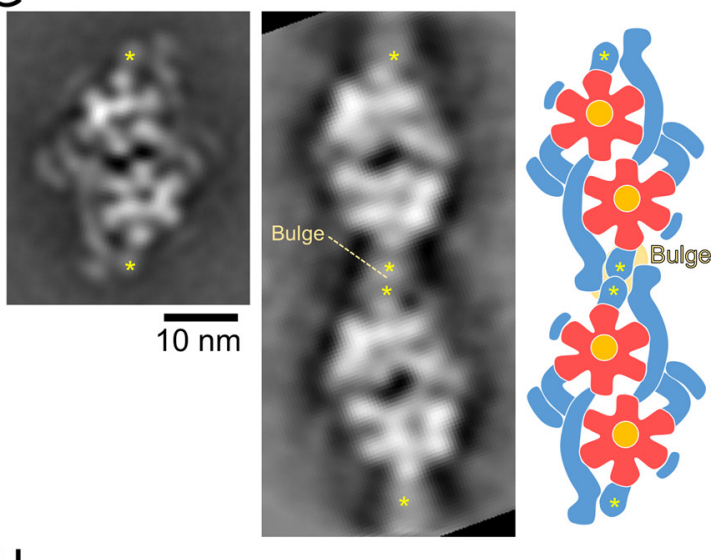

$\mathrm{H}$
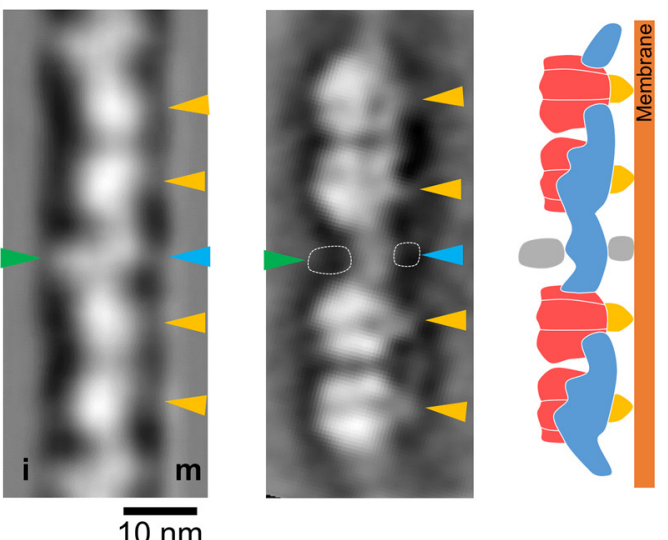

(d)

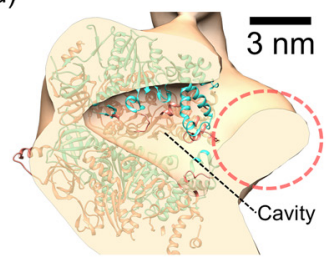

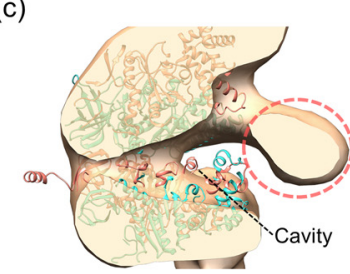

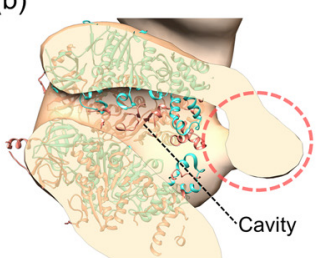

FIG 5 Chain structure. (A) Electron micrograph of a negatively stained chain. The chain structures are marked by blue lines. (B) Magnified chain images. (C) Representative 2D averaged images. (D) Three-dimensional reconstruction of a chain containing 


\section{DISCUSSION}

Outline of the internal structure of gliding machinery. Previously, sequence analysis suggested that the chain of $M$. mobile gliding machinery evolved from $F_{1}$-ATPase $(5,23-26)$. The present study supports this conclusion with structural data showing that the chain has hexameric rings similar to the $\mathrm{F}_{1}$-ATPase catalytic $(\alpha \beta)_{3}$. Integrating available information, we can now describe the outline of the internal structure of the M. mobile gliding machinery (Fig. 1A). M. mobile cells have 28 individual 530-nm-long chains, each of which contains 17 dimer units composed of two $F_{1}$-like ATPases and filamentous structures (23). The central stalk of the $F_{1}$-like ATPase and another protrusion from the connecting bulge project to the cell membrane.

Unique role of the $\mathbf{F}_{\mathbf{1}}$-ATPase-related complex. To date, several complexes are known to be evolutionarily related to $F_{1}$-ATPase, all of which are responsible for transporting substances across the membrane (40). However, the motor we identified here most likely plays a role in motility. This case may be reminiscent of that for dynein, a motor in eukaryotes, which evolved from a widely conserved AAA (ATPases associated with diverse cellular activities) + protein, in which multiple subunits of ATPases perform functional rotation $(41,42)$. Sequence analyses have shown that mycoplasma type 3 ATPase is also related to $F_{1}$-ATPase, and its role has been suggested to promote substrate turnover in the MIBMIP system (33). If type 3 ATPase provides the force to change the conformation of a hydrolytic enzyme, its role in force generation is common with that of type 2, the gliding motor.

$F_{1} F_{o}$-ATPases are known to be dimerized through interactions between $F_{0}$ domains and are usually arranged in rows along the short axis in the tightly curved crista ridges of mitochondria $(31,43,44)$. The dimer structure found in the present study is not related to this, because the $F_{1}$-like domain is dimerized through the filament structure and is linked in the long-axis direction. However, some roles may be common, in part, if the dimerization and chain formation observed in the gliding motor identified in this study stabilize the membrane structure, as seen in the $F_{1} F_{0}$-ATPase dimer (45). Moreover, dimerization may result in cooperativity in motor functions.

Protein assignment. The $\alpha$-subunit homolog MMOB1660 (58.7 kDa) and the $\beta$-subunit homolog MMOB1670 (88.4 kDa) likely correspond to the smaller and larger subunits, respectively, of the hexameric ring of an $F_{1}$-like ATPase unit, as suggested by the estimated 1:1 molar ratio in the dimer (Fig. $2 \mathrm{~A}$ and $4 \mathrm{C}$ ). This means that the hook structure of the larger subunit may be formed by the extra N-terminal region $(34.8 \mathrm{kDa})$ of MMOB1670. Previously, 3D structure modeling based on secondary structure suggested that MMOB1630 is structurally similar to the $\gamma$ subunit, the principal component of the central stalk of $F_{1}$-ATPase (5). In general, the $\gamma$ subunit of $F_{1}$-ATPase is composed of a coiled-coil and a globular domain and penetrates the hexameric ring (46). In the $F_{1}$-like ATPase unit and chain 3D model, a stalk structure, suggesting the globular domain of the $\gamma$ subunit, was found in the center of the hexameric ring (Fig. $4 \mathrm{C}$ and 5F), implying that MMOB1630 penetrates the hexameric ring like the $\gamma$ subunit.

Using HS-AFM observations, the peak at approximately $5 \mathrm{~nm}$ at the center of the hexameric ring dropped out with time (Fig. 3I). The peak height agrees with the length of the

FIG 5 Legend (Continued)

two $F_{1}$-like ATPase dimers. The 3D map is visualized at a density threshold (contour level $=0.026$ ). The central stalks are marked by open triangles. (E) Superposition of the atomic model of Bacillus $\mathrm{F}_{1}$-ATPase catalytic $(\alpha \beta)_{3}$ (PDB ID 6N2Y) (38) onto the 3D chain structure. The $\alpha$ and $\beta$ subunits are colored salmon and turquoise, respectively. The central stalk and protrusions from hexameric rings are marked by open and black triangles, respectively. (F) Cross section of mushroom-like structures. Central stalks are marked by broken circles. The double-headed arrow shows the length of the protrusion. Corresponding mushroomlike structures are marked ( $a$ to $d$ ) in panel $E$. (G) Comparison between the dimer image from Fig. 3C (left) and the chain reprojection (middle). The reprojected image is viewed from the angle used for the right image of panel $D$. Short filaments corresponding to the position of the connecting bulge are marked by asterisks. A depiction of a chain model based on the comparison (right). (H) Comparison between the averaged chain image from ECT (left) and the chain reprojection (middle). (Left) The averaged chain image was modified from the whole-cell ECT image in a previous study (23). Inner and membrane sides relative to the chain are marked by $\mathrm{i}$ and $\mathrm{m}$, respectively. (Middle) Chain was reprojected from an angle close to the middle image in panel D. The protrusion from the globule corresponding to the central stalk from the hexameric ring, one from the connecting bulge, and the globule attached to the connecting bulge are marked by orange, light blue, and green triangles, respectively. The areas of image densities that were visualized only in the ECT image are marked by broken lines. (Right) An illustration depicts a chain model based on the comparison. 
estimated globular domain of MMOB1630 in the chain 3D model (Fig. 3J and 5F), suggesting that the peak is composed of MMOB1630 and was pulled out from the hexameric ring by the scanning cantilever during HS-AFM observation. The pullout event is thought to be common to that of the $F_{1}$-ATPase, in which the $\gamma$ subunit is removed from the hexameric ring by optical tweezers (47). The filamentous structures around the hexameric ring probably correspond to lateral protrusions in the HS-AFM images and are formed by the remaining proteins, MMOB1620 and MMOB4530 (PGK). These proteins probably play roles in ATPase dimerization, chain formation, and lateral chain interaction (23). MMOB1620 is an unannotated protein specific to the type 2 ATPase cluster $(26,32)$. MMOB4530 is annotated as an enzyme that transfers phosphate groups from 1,3-bisphosphoglycerate to ADP in glycolysis to yield ATP and 3-phosphoglycerate (48). In M. mobile, ATP is probably provided by glycolysis (49). MMOB4530 may supply ATP efficiently to the gliding motor by its close proximity. Yeast V-ATPase, which belongs to the rotary ATPase family-like $F_{1} F_{0}$-ATPase, is also attached by two glycolytic enzymes, 6-phosphofructo-1-kinase and aldolase (50-52). These glycolytic enzymes are involved in the regulation of V-ATPase assembly and activity.

Ten proteins have been identified as the components of the internal structure (Fig. 1) $(23,24,26)$. In the present study, we identified five proteins as the dimer components. The other five proteins are likely involved in other parts, for example, the "bell" at the front part of the internal structure (Fig. 1A) and parts of the intact chain structure, which were lost in the fractionation (Fig. $5 \mathrm{H}$ ).

Possible force transmission mechanisms for gliding. The involvement of an internal ATPase in the gliding mechanism is based on the following five observations from the analysis of the "gliding head" of $M$. mobile protrusions and of the isolated gliding machinery. (a) The affinity for ATP estimated by the saturation extent is comparable between the ATPase activity of the internal structure and the speed of the gliding head (23). (b) Substrate binding and gliding speed of the gliding head are inhibited by azide as well as the ATPase activity of the internal structure (23). (c) The chain in the internal structure undergoes conformational changes based on ATP hydrolysis $(23,53)$. (d) Among the 21 proteins identified from the gliding head, only MMOB1660 and -1670 could be suggested for ATPase activity from the amino acid sequences alone $(23,24)$. (e) Fluorescent protein tagging of components of the internal structure significantly affects the substrate binding of cell and the gliding speed (26).

The structure elucidated in the present study allows us to discuss the gliding mechanism in more detail. In $\mathrm{F}_{1}$-ATPase, the three catalytic sites in the hexameric ring cooperatively hydrolyze ATP, and each catalytic $\beta$ subunit undergoes a conformational change that drives the rotation of the central stalk (46). Previously, structural changes linked to ATP hydrolysis were reported: (I) EM studies showed 2-nm contraction of dimer intervals in the isolated chains (23), and (II) HS-AFM studies showed movements of individual dimers in the cell $9 \mathrm{~nm}$ perpendicular to the chain long axis and $2 \mathrm{~nm}$ into the cell (53). Considering these observations, we propose two different working models for the force transmission mechanism in gliding (Fig. 6). In the "contraction model" (Fig. 6, i), the force generated by the hexameric ring shortens the chain. The resulting displacement of the projections from the dimer to the cell membrane drives the hook structure of Gli521 like a lever. Then, the leg moves with the catch, pull, and release of the SOs. In the "rotation model" (Fig. 6, ii), the force generated by the hexameric ring rotates $\mathrm{MMOB} 1630$ in the same way as $\mathrm{F}_{1}$-ATPase. This rotation is transmitted across the cell membrane to Gli521. The hook structure converts rotational motion into linear motion of the leg, similar to a crank. Previous studies have reported that M. mobile exhibits unitary steps of approximately $70 \mathrm{~nm}$ in size at no load $(29,54)$. In our models, both the rotation and contraction displacements are expected to be a few nanometers. These displacements may be amplified by the large surface structure complex formed by the 100-nm-long Gli349 and 120-nm-long Gli521, which show dimensions comparable to the step size, acting as a large gear (22). This conjecture could explain how a single leg exerts a force of $1.5 \mathrm{pN}$, smaller than that of conventional motor proteins such as myosin, dynein, and kinesin. 


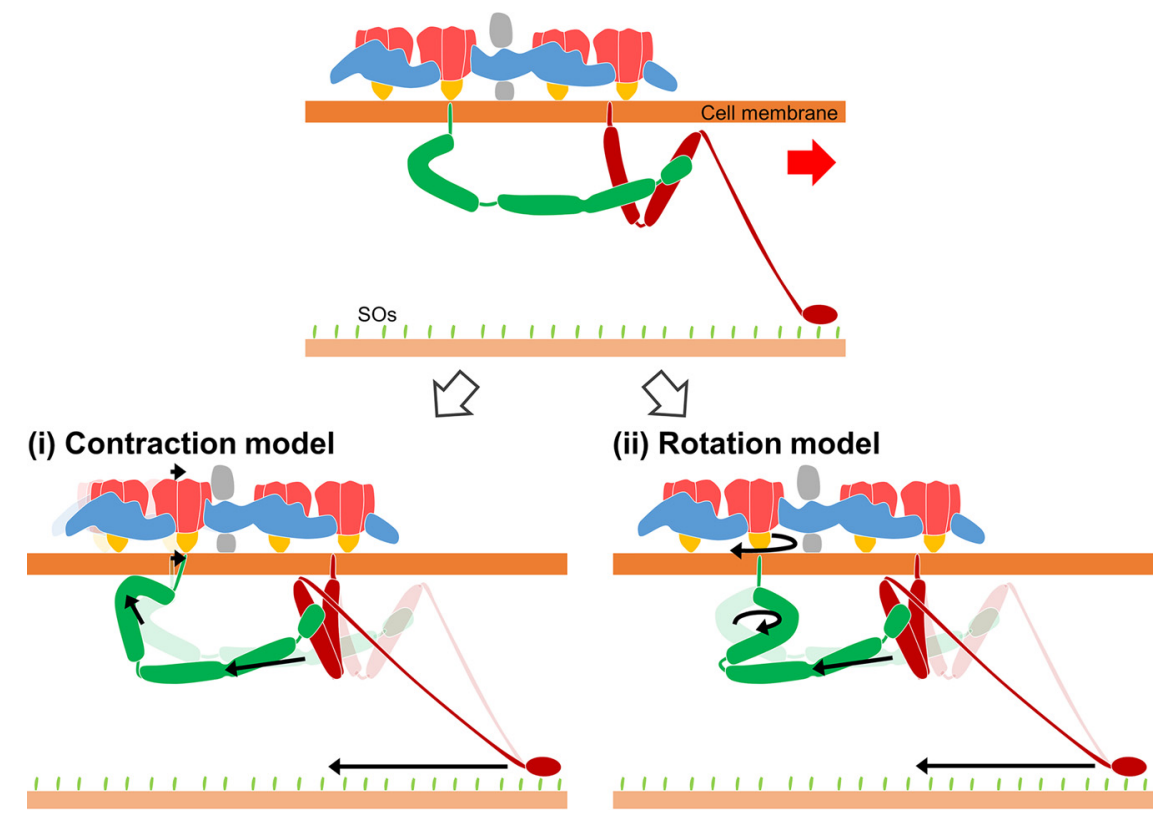

FIG 6 Working models for force transmission mechanism. The gliding direction is indicated by a red arrow. The regions marked in gray were visualized only in the ECT image. The crank protein Gli521 and the leg protein Gli349 are colored green and red, respectively. (i) Contraction model: the force generated by the hexameric ring displaces the dimer along the gliding direction. The displacements are transmitted through the membrane to Gli521. (ii) Rotation model: the force generated by the hexameric ring rotates the central stalk in a mechanism similar to that of $F_{1}$-ATPase. The rotational motion is transmitted across the membrane to Gli521. The generation and transmission of forces are presented by black arrows for both models.

Evolution of $\boldsymbol{M}$. mobile gliding. A previous study suggested that Gli349 evolved from a static binding receptor to parasitize the host (16). Considering this, the evolutionary origin of $M$. mobile gliding can now be discussed. $\mathrm{F}_{1} \mathrm{~F}_{\mathrm{o}}$-ATPase, which is abundant on the cell membrane, could have been accidentally associated with the binding receptor and turned into a primitive motility system, which may have provided random cell spreading. The system was then refined under survival pressure, because motility might be beneficial for infection and evading the host's immune system. For dimerization and chain formation, PGK was then incorporated into the gliding machinery, because PGK was working in close proximity to $F_{1} F_{0}$-ATPase.

\section{MATERIALS AND METHODS}

Strains and culture conditions. We used P476R gli521, a mutant strain of M. mobile that can glide normally but binds SOs more tightly than wild-type strains $(10,22,28) . M$. mobile cells were cultured as described previously $(55,56)$.

Optical microscopy. The cultured cells were inserted into a tunnel chamber assembled with two coverslips and double-sided tape and observed by phase-contrast microscopy using an inverted microscope (IX71; Olympus, Tokyo, Japan) $(17,19)$. Movement was recorded using a complementary metal-oxide semiconductor (CMOS) camera (DMK33UX174; The Imaging Source, Bremen, Germany). Video was analyzed using ImageJ software, version 1.53a (https://imagej.nih.gov/ij/).

Solubility test. All procedures for fractionation were performed at $4^{\circ} \mathrm{C}$ unless otherwise noted, and focused protein bands were identified by peptide mass fingerprinting (PMF), as previously reported (24, 57). To investigate the solubility of the chain components, M. mobile cells from $60 \mathrm{ml}$ of culture medium were collected by centrifugation at $14,000 \times g$ for $20 \mathrm{~min}$ and washed twice with phosphate-buffered saline (PBS) consisting of $8.1 \mathrm{mM} \mathrm{Na}_{2} \mathrm{HPO}_{4}, 1.5 \mathrm{mM} \mathrm{KH}_{2} \mathrm{PO}_{4}(\mathrm{pH} 7.3), 2.7 \mathrm{mM} \mathrm{KCl}$, and $137 \mathrm{mM} \mathrm{NaCl}$. Cells were resuspended in PBS to a 12-fold higher concentration than the culture and sonicated for $1 \mathrm{~min}$ at 24 to $27^{\circ} \mathrm{C}$ to be dispersed in microtubes using an ultrasonic generator (2510 J-MT; BRANSON, Kanagawa, Japan). The cells were then treated with Triton solution ( $1 \%$ Triton X-100, $0.1 \mathrm{mg} / \mathrm{ml}$ DNase, $5 \mathrm{mM} \mathrm{MgCl}{ }_{2}$, and $1 \mathrm{mM}$ phenylmethylsulfonyl fluoride in PBS) in a total volume of $10 \mathrm{ml}$. After gentle shaking for $1 \mathrm{~h}$, the suspensions were centrifuged at 20,000 $\times g$ for $20 \mathrm{~min}$, and pellets were collected and washed once with suspension buffer (PBS including $5 \mathrm{mM} \mathrm{MgCl}_{2}$ ). This fraction was pellet-1. Pellet-1 was then resuspended separately in suspension buffer adjusted to contain different concentrations of 
$\mathrm{NaCl}(0,50,137,200$, and $400 \mathrm{mM})$ by pipetting several times. After treatment for $8 \mathrm{~h}$, suspensions were centrifuged at $20,000 \times g$ for $20 \mathrm{~min}$, and supernatants and pellets were collected for SDS-PAGE analysis.

Preparation of fractions. For isolation of the dimer, pellet-1 from a 1.2-liter culture was resuspended in $5 \mathrm{ml}$ suspension buffer by pipetting up and down and allowed to dissolve for $8 \mathrm{~h}$. The soluble fraction was collected by centrifugation at $20,000 \times g$ for $20 \mathrm{~min}$ and loaded onto a HiLoad 16/600 Superdex 200 column (Cytiva, Tokyo, Japan) equilibrated with $1 \mathrm{mM} \mathrm{MgCl}$ in PBS at a flow rate of $0.8 \mathrm{ml} / \mathrm{min}$. The fractions were analyzed by SDS-PAGE and Coomassie brilliant blue (CBB) staining.

For isolation of the monomer, pellet-1 from a 1.2-liter culture was suspended in $5 \mathrm{ml}$ Tris buffer consisting of $20 \mathrm{mM}$ Tris- $\mathrm{HCl}$ (pH 7.5), $250 \mathrm{mM} \mathrm{NaCl}, 1 \mathrm{mM}$ phenylmethylsulfonyl fluoride, and $1 \mathrm{mM} \mathrm{MgCl}$ by pipetting and allowed to dissolve for $8 \mathrm{~h}$. The soluble fraction was collected by centrifugation at $20,000 \times g$ for $20 \mathrm{~min}$ and mixed with $1.5 \%$ (wt/vol) sodium cholate. After $7 \mathrm{~h}$ of incubation, the complexes were loaded onto a Sephacryl S-400 HR column (Cytiva) equilibrated with $0.7 \%$ sodium cholate, $20 \mathrm{mM}$ Tris- $\mathrm{HCl}(\mathrm{pH} 7.5), 250 \mathrm{mM} \mathrm{NaCl}$, and $1 \mathrm{mM} \mathrm{MgCl}_{2}$ at a flow rate of $0.5 \mathrm{ml} / \mathrm{min}$. The fractions were analyzed by SDS-PAGE and CBB and reverse staining $(58,59)$. The fraction of the complex composed of MMOB1670, -1660, and -1630 was collected. Samples were concentrated using an Amicon Ultra $100 \mathrm{~K}$ spin filter (Merck KGaA, Darmstadt, Germany), if necessary.

For isolation of the chain, pellet-1 from a 15-ml culture was resuspended in $60 \mu$ l suspension buffer. The suspension was then gently mixed with an equal volume of suspension buffer adjusted to contain $637 \mathrm{mM} \mathrm{NaCl}$. The chain was recovered as the supernatant by centrifugation at 5,000 $\times g$ for $5 \mathrm{~min}$.

Analytical gel filtration. The dimer solution was loaded onto a Sephacryl S-400 HR column equilibrated with gel filtration buffer containing $20 \mathrm{mM}$ Tris- $\mathrm{HCl}(\mathrm{pH} 7.5), 200 \mathrm{mM} \mathrm{NaCl}$, and $1 \mathrm{mM} \mathrm{MgCl} \mathrm{M}_{2}$ at a flow rate of $0.5 \mathrm{ml} / \mathrm{min}$ at $4^{\circ} \mathrm{C}$. Thyroglobulin $(669 \mathrm{kDa}$; gel filtration calibration kit; Cytiva) was dissolved in gel filtration buffer and loaded onto the column as a size standard at a flow rate of $0.5 \mathrm{ml} / \mathrm{min}$. The stoichiometry of protein complexes was estimated by densitometry of SDS-PAGE gels stained with CBB, using a scanner (GT-9800F; Epson, Nagano, Japan) and ImageJ (9).

BN-PAGE and in-gel ATPase activity assays. BN-PAGE was performed according to the user manual of the NativePAGE Novex bis-Tris gel system (Thermo Fisher Scientific, Waltham, MA). For BN-PAGE of sodium cholate (SC)-treated dimer, a dimer fraction was mixed with sodium cholate (1.5\%) and incubated at $4^{\circ} \mathrm{C}$ for $9 \mathrm{~h}$. When this sample was mixed with a sample buffer, NativePAGE 5\% (wt/vol) G-250 sample additive was also added at $0.5 \%$ (wt/vol) to prevent protein aggregation. Thyroglobulin was dissolved in water and used as a negative control for the in-gel ATPase activity assay. For the in-gel ATPase activity assay $(60,61)$, native gels were incubated with gentle shaking for $8 \mathrm{~h}$ at 24 to $27^{\circ} \mathrm{C}$ in activity buffer containing $270 \mathrm{mM}$ glycine, $35 \mathrm{mM}$ Tris ( $\mathrm{pH} 8.4$ ), $4 \mathrm{mM} \mathrm{ATP}, 14 \mathrm{mM} \mathrm{MgSO}$, and $0.2 \%$ (wt/vol) $\mathrm{Pb}\left(\mathrm{NO}_{3}\right)_{2}$. The gels were rinsed once with water, and images were taken using an ImageQuant LAS 4000 mini (Cytiva). White precipitates were then dissolved by gentle shaking for $8 \mathrm{~h}$ at 24 to $27^{\circ} \mathrm{C}$ with $50 \%$ (vol/vol) methanol and $10 \%$ (vol/vol) acetic acid in water. The gels were restained with $0.025 \%$ (wt/vol) CBB G-250 and $10 \%$ acetic acid in water for $80 \mathrm{~min}$ at 24 to $27^{\circ} \mathrm{C}$ with gentle shaking and destained with $10 \%$ (vol/vol) ethanol and $10 \%$ acetic acid in water for $180 \mathrm{~min}$ at 24 to $27^{\circ} \mathrm{C}$ with gentle shaking. The gels were rinsed once with water, and images were taken using an ImageQuant LAS 4000 mini.

Phosphate-release assay. Dimer solution was dialyzed for $8 \mathrm{~h}$ using $20 \mathrm{mM} \mathrm{Tris-HCl}(\mathrm{pH} 7.5)$, $150 \mathrm{mM} \mathrm{NaCl}$, and $2 \mathrm{mM} \mathrm{MgCl}$. ATPase activity was assayed by a continuous spectrophotometric method using a 2-amino-6-mercapto-7-methylpurine ribonucleoside-purine nucleoside phosphorylase reaction to detect released inorganic phosphate (EnzChek kit; Thermo Fisher Scientific) (62). The reaction mixture was as follows: $15.7 \mathrm{nM}$ dimer, $20 \mathrm{mM}$ Tris- $\mathrm{HCl}(\mathrm{pH} 7.5), 150 \mathrm{mM} \mathrm{NaCl}, 2 \mathrm{mM} \mathrm{MgCl}$, and 0.01 to $1 \mathrm{mM}$ ATP in a total volume of $0.2 \mathrm{ml}$ at $25^{\circ} \mathrm{C}$. Sodium azide was added to $15.4 \mathrm{mM}$ final concentration when the reaction was started. The protein amount of the MMOB1670 comprising $\mathrm{F}_{1}$-ATPase $\beta$-subunit homologs was estimated using densitometric analysis of SDS-PAGE gels.

Negative-staining EM and image processing. Dimer solution was placed on a glow-discharged (PIB-10; VACUUM DEVICE, Ibaraki, Japan) carbon-coated grid (F-400; Nisshin EM Co., Tokyo, Japan) and incubated for $1 \mathrm{~min}$ at 24 to $27^{\circ} \mathrm{C}$. The solution was then removed, and the grid was stained with $2 \%$ uranyl acetate (wt/vol) for $30 \mathrm{~s}$. The stain was then removed, and the grid was air dried. To observe the monomer and chain, the grids were washed with water after 1 min of incubation and then treated as described for the dimer solution. Samples were observed using a transmission EM (JEM1010; JEOL) at $80 \mathrm{kV}$, equipped with a FastScan-F214 (T) charge-coupled-device (CCD) camera (TVIPS, Gauting, Germany), and images were captured at $2.58 \AA$ A pixel.

The contrast transfer function parameters for electron micrographs were estimated using Gctf (63). Further image processing was performed using RELION 3.0 (35). A total of 2,148 particles for the dimer and 11,687 particles for the monomer were automatically selected with box sizes of 180 by 180 and 100 by 100 pixels, respectively, using reference-based auto picking. These particle images were binned to $5.16 \AA$ / pixel. For the dimer, the particle images were 2D classified into 100 classes. For the monomer, particle images were 2D classified in four rounds, and the selected 7,381 particles were reextracted with the pixel size returned to the unbinned image and then 2D classified into 50 classes.

For reconstruction of the 3D chain structure, 2,127 particles were manually selected for chains with a box size of 276 by 276 pixels with $\sim 50 \%$ overlap. These particle images were binned to $5.16 \AA ̊$ /pixel. Particle images were 2D classified in two rounds, and the selected 1,709 particles were used to reconstruct the initial model with a final resolution limit of $50 \AA$. The initial model and selected particles were used to perform 3D refinement. Reprojection images were produced from the 3D map using the relion_project command in RELION. The 3D map was visualized using UCSF Chimera 1.14 (64). Atomic models of $\mathrm{F}_{1}$-ATPase catalytic $(\alpha \beta)_{3}$ from Bacillus PS3 (PDB ID 6N2Y) (38) were fitted into the 3D map using the command "Fit in map" in UCSF Chimera. 
HS-AFM. Imaging was performed with a laboratory-built tapping-mode $\operatorname{HS}-\operatorname{AFM}(65,66)$, using small cantilevers (BLAC10DS-A2; Olympus) with resonant frequency of $\sim 0.5 \mathrm{MHz}$ in water, quality factor of $\sim 1.5$ in water, and spring constant of $\sim 0.1 \mathrm{~N} / \mathrm{m}$. The cantilever's free oscillation peak-topeak amplitude $\left(A_{0}\right)$ and set-point amplitude were set at $\sim 2.5 \mathrm{~nm}$ and $\sim 0.8 \times A_{0}$, respectively. The probe tip was grown on the original tip end of a cantilever through electron beam deposition and further sharpened using a radio frequency plasma etcher (PE-2000; South Bay Technology, Redondo Beach, CA) under an argon gas atmosphere (typically at $180 \mathrm{mTorr}$ and $15 \mathrm{~W}$ for $3 \mathrm{~min}$ ). The sample was deposited on a freshly cleaved mica disc glued to a glass stage beforehand. After $3.5 \mathrm{~min}$, the stage surface was immersed in a liquid cell containing an observation buffer consisting of $20 \mathrm{mM}$ Tris- $\mathrm{HCl}(\mathrm{pH} 7.5), 50 \mathrm{mM} \mathrm{KCl}$, and $2 \mathrm{mM} \mathrm{MgCl}$. Imaging was performed at 24 to $27^{\circ} \mathrm{C}$. AFM images were processed using a low-pass filter to remove spike noise and make the $x y$ plane flat and analyzed using Kodec software (version 4.4.7.39) (67). Surface profiles and smoothing were performed using ImageJ software.

Data availability. The density map has been deposited in the Electron Microscopy Data Bank with accession code EMD-31520.

\section{SUPPLEMENTAL MATERIAL}

Supplemental material is available online only.

MOVIE S1, AVI file, 0.4 MB.

MOVIE S2, AVI file, 0.4 MB.

MOVIE S3, AVI file, 1.4 MB.

MOVIE S4, AVI file, $0.2 \mathrm{MB}$.

FIG S1, PDF file, $0.1 \mathrm{MB}$.

FIG S2, PDF file, $0.1 \mathrm{MB}$.

FIG S3, PDF file, 0.7 MB.

FIG S4, PDF file, $0.1 \mathrm{MB}$.

FIG S5, PDF file, 0.2 MB.

FIG S6, PDF file, 0.4 MB.

\section{ACKNOWLEDGMENTS}

We thank Toshiaki Arata, Ikuko Fujiwara, Kohei Kobayashi, and Hiroki Sato at the Graduate School of Science, Osaka City University, and Takayuki Uchihashi at the Department of Physics and Structural Biology Research Center, Nagoya University, for helpful discussions. We also thank Aya Takamori at the Graduate School of Science, Osaka City University, for performing matrix-assisted laser desorption ionization-time of flight (MALDI-TOF) mass spectrometry. T.T. learned RELION software in an instruction course on 20180927 to 28 provided by the Cyclic Innovation for Clinical Empowerment (CiCLE) from AMED.

This work was supported by a grant-in-aid for scientific research on the Innovative Area Harmonized Supramolecular Motility Machinery and Its Diversity (MEXT KAKENHI grant number JP24117002), by grants-in-aid for scientific research (B) and (A) (MEXT KAKENHI grant numbers JP24390107 and JP17H01544), by JST CREST grant number JPMJCR19S5, Japan, by the Osaka City University (OCU) Strategic Research Grant 2018 for top priority researches, and by a grant-in-aid of the Fugaku Trust for Medicinal Research to M.M. and JSPS KAKENHI (grant number JP25000013), the Platform Project for Supporting Drug Discovery and Life Science Research (BINDS) from AMED (grant number JP19am0101117 and support number 1282), CiCLE (grant number JP17pc0101020), and JEOL YOKOGUSHI Research Alliance Laboratories of Osaka University to K.N.

\section{REFERENCES}

1. Razin S, Hayflick L. 2010. Highlights of mycoplasma research-an historical perspective. Biologicals 38:183-190. https://doi.org/10.1016/j.biologicals 2009.11.008.

2. Grosjean $H$, Breton $M$, Sirand-Pugnet $P$, Tardy F, Thiaucourt F, Citti C, Barre A, Yoshizawa S, Fourmy D, de Crecy-Lagard V, Blanchard A. 2014. Predicting the minimal translation apparatus: lessons from the reductive evolution of mollicutes. PLoS Genet 10:e1004363. https://doi.org/10 .1371/journal.pgen.1004363.

3. Miyata $M$, Robinson RC, Uyeda TQP, Fukumori $Y$, Fukushima SI, Haruta $S$, Homma M, Inaba K, Ito M, Kaito C, Kato K, Kenri T, Kinosita Y, Kojima S,
Minamino T, Mori H, Nakamura S, Nakane D, Nakayama K, Nishiyama M, Shibata S, Shimabukuro K, Tamakoshi M, Taoka A, Tashiro Y, Tulum I, Wada H, Wakabayashi KI. 2020. Tree of motility - a proposed history of motility systems in the tree of life. Genes Cells 25:6-21. https://doi.org/10.1111/gtc.12737.

4. Miyata M. 2010. Unique centipede mechanism of Mycoplasma gliding. Annu Rev Microbiol 64:519-537. https://doi.org/10.1146/annurev.micro .112408.134116.

5. Miyata M, Hamaguchi T. 2016. Prospects for the gliding mechanism of Mycoplasma mobile. Curr Opin Microbiol 29:15-21. https://doi.org/10.1016/j mib.2015.08.010. 
6. Miyata M, Hamaguchi T. 2016. Integrated information and prospects for gliding mechanism of the pathogenic bacterium Mycoplasma pneumoniae. Front Microbiol 7:960. https://doi.org/10.3389/fmicb.2016.00960.

7. Uenoyama A, Kusumoto A, Miyata M. 2004. Identification of a 349-kilodalton protein (Gli349) responsible for cytadherence and glass binding during gliding of Mycoplasma mobile. J Bacteriol 186:1537-1545. https://doi .org/10.1128/JB.186.5.1537-1545.2004.

8. Seto S, Uenoyama A, Miyata M. 2005. Identification of a 521-kilodalton protein (Gli521) involved in force generation or force transmission for Mycoplasma mobile gliding. J Bacteriol 187:3502-3510. https://doi.org/10 .1128/JB.187.10.3502-3510.2005.

9. Uenoyama A, Miyata M. 2005. Identification of a 123-kilodalton protein (Gli123) involved in machinery for gliding motility of Mycoplasma mobile. J Bacteriol 187:5578-5584. https://doi.org/10.1128/JB.187.16.5578-5584 .2005 .

10. Uenoyama A, Seto S, Nakane D, Miyata M. 2009. Regions on Gli349 and Gli521 protein molecules directly involved in movements of Mycoplasma mobile gliding machinery, suggested by use of inhibitory antibodies and mutants. J Bacteriol 191:1982-1985. https://doi.org/10.1128/JB.01012-08.

11. Kusumoto A, Seto S, Jaffe JD, Miyata M. 2004. Cell surface differentiation of Mycoplasma mobile visualized by surface protein localization. Microbiology (Reading) 150:4001-4008. https://doi.org/10.1099/mic.0.27436-0.

12. Miyata M, Petersen JD. 2004. Spike structure at the interface between gliding Mycoplasma mobile cells and glass surfaces visualized by rapidfreeze-and-fracture electron microscopy. J Bacteriol 186:4382-4386. https://doi.org/10.1128/JB.186.13.4382-4386.2004.

13. Adan-Kubo J, Uenoyama A, Arata T, Miyata M. 2006. Morphology of isolated Gli349, a leg protein responsible for Mycoplasma mobile gliding via glass binding, revealed by rotary shadowing electron microscopy. J Bacteriol 188:2821-2828. https://doi.org/10.1128/JB.188.8.2821-2828.2006.

14. Lesoil C, Nonaka T, Sekiguchi H, Osada T, Miyata M, Afrin R, Ikai A. 2010. Molecular shape and binding force of Mycoplasma mobile's leg protein Gli349 revealed by an AFM study. Biochem Biophys Res Commun 391:1312-1317. https://doi.org/10.1016/j.bbrc.2009.12.023.

15. Metsugi S, Uenoyama A, Adan-Kubo J, Miyata M, Yura K, Kono H, Go N. 2005. Sequence analysis of the gliding protein Gli349 in Mycoplasma mobile. Biophysics (Nagoya-Shi) 1:33-43. https://doi.org/10.2142/biophysics .1.33.

16. Hamaguchi T, Kawakami M, Furukawa H, Miyata M. 2019. Identification of novel protein domain for sialyloligosaccharide binding essential to $\mathrm{MycO}$ plasma mobile gliding. FEMS Microbiol Lett 366:fnz016. https://doi.org/10 .1093/femsle/fnz016.

17. Morio H, Kasai T, Miyata M. 2016. Gliding direction of Mycoplasma mobile. J Bacteriol 198:283-290. https://doi.org/10.1128/JB.00499-15.

18. Kasai T, Hamaguchi T, Miyata M. 2015. Gliding motility of Mycoplasma mobile on uniform oligosaccharides. J Bacteriol 197:2952-2957. https://doi .org/10.1128/JB.00335-15.

19. Kasai T, Nakane D, Ishida H, Ando H, Kiso M, Miyata M. 2013. Role of binding in Mycoplasma mobile and Mycoplasma pneumoniae gliding analyzed through inhibition by synthesized sialylated compounds. J Bacteriol 195:429-435. https://doi.org/10.1128/JB.01141-12.

20. Nagai R, Miyata M. 2006. Gliding motility of Mycoplasma mobile can occur by repeated binding to $N$-acetylneuraminyllactose (sialyllactose) fixed on solid surfaces. J Bacteriol 188:6469-6475. https://doi.org/10 .1128/JB.00754-06.

21. Chen J, Neu J, Miyata M, Oster G. 2009. Motor-substrate interactions in Mycoplasma motility explains non-Arrhenius temperature dependence. Biophys J 97:2930-2938. https://doi.org/10.1016/j.bpj.2009.09.020.

22. Mizutani M, Tulum I, Kinosita Y, Nishizaka T, Miyata M. 2018. Detailed analyses of stall force generation in Mycoplasma mobile gliding. Biophys J 114:1411-1419. https://doi.org/10.1016/j.bpj.2018.01.029.

23. Nishikawa M, Nakane D, Toyonaga T, Kawamoto A, Kato T, Namba K, Miyata M. 2019. Refined mechanism of Mycoplasma mobile gliding based on structure, ATPase activity, and sialic acid binding of machinery. mBio 10:e02846-19. https://doi.org/10.1128/mBio.02846-19.

24. Nakane D, Miyata M. 2007. Cytoskeletal "jellyfish" structure of Mycoplasma mobile. Proc Natl Acad Sci U S A 104:19518-19523. https://doi .org/10.1073/pnas.0704280104.

25. Tulum I, Yabe M, Uenoyama A, Miyata M. 2014. Localization of P42 and $\mathrm{F}_{1}$-ATPase alpha-subunit homolog of the gliding machinery in Mycoplasma mobile revealed by newly developed gene manipulation and fluorescent protein tagging. J Bacteriol 196:1815-1824. https://doi.org/10 .1128/JB.01418-13.
26. Tulum I, Kimura K, Miyata M. 2020. Identification and sequence analyses of the gliding machinery proteins from Mycoplasma mobile. Sci Rep 10:3792. https://doi.org/10.1038/s41598-020-60535-z.

27. Walker JE, Saraste M, Runswick MJ, Gay NJ. 1982. Distantly related sequences in the alpha- and beta-subunits of ATP synthase, myosin, kinases and other ATP-requiring enzymes and a common nucleotide binding fold. EMBO J 1:945-951. https://doi.org/10.1002/j.1460-2075.1982 .tb01276.x.

28. Uenoyama A, Miyata M. 2005. Gliding ghosts of Mycoplasma mobile. Proc Natl Acad Sci U S A 102:12754-12758. https://doi.org/10.1073/pnas .0506114102 .

29. Kinosita Y, Nakane D, Sugawa M, Masaike T, Mizutani K, Miyata M, Nishizaka T. 2014. Unitary step of gliding machinery in Mycoplasma mobile. Proc Natl Acad Sci U S A 111:8601-8606. https://doi.org/10.1073/ pnas.1310355111.

30. Abrahams JP, Leslie AG, Lutter R, Walker JE. 1994. Structure at 2.8 Å resolution of $F_{1}$-ATPase from bovine heart mitochondria. Nature 370:621-628. https://doi.org/10.1038/370621a0.

31. Kühlbrandt W. 2019. Structure and mechanisms of F-type ATP synthases. Annu Rev Biochem 88:515-549. https://doi.org/10.1146/annurev-biochem -013118-110903.

32. Beven L, Charenton C, Dautant A, Bouyssou G, Labroussaa F, Skollermo A, Persson A, Blanchard A, Sirand-Pugnet P. 2012. Specific evolution of $F_{1}$ like ATPases in mycoplasmas. PLoS One 7:e38793. https://doi.org/10 .1371/journal.pone.0038793.

33. Nottelet $P$, Bataille $L$, Gourgues $G$, Anger R, Lartigue $C$, Sirand-Pugnet $P$, Marza E, Fronzes R, Arfi Y. 2021. The mycoplasma surface proteins MIB and MIP promote the dissociation of the antibody-antigen interaction. Sci Adv 7:eabf2403. https://doi.org/10.1126/sciadv.abf2403.

34. Bowler MW, Montgomery MG, Leslie AG, Walker JE. 2006. How azide inhibits ATP hydrolysis by the F-ATPases. Proc Natl Acad Sci U S A 103:8646-8649. https://doi.org/10.1073/pnas.0602915103.

35. Zivanov J, Nakane T, Forsberg BO, Kimanius D, Hagen WJ, Lindahl E, Scheres SH. 2018. New tools for automated high-resolution cryo-EM structure determination in RELION-3. Elife 7:e42166. https://doi.org/10 .7554/eLife.42166.

36. Ando T. 2018. High-speed atomic force microscopy and its future prospects. Biophys Rev 10:285-292. https://doi.org/10.1007/s12551 -017-0356-5.

37. Uchihashi T, lino R, Ando T, Noji H. 2011. High-speed atomic force microscopy reveals rotary catalysis of rotorless $F_{1}$-ATPase. Science 333:755-758. https://doi.org/10.1126/science.1205510.

38. Guo H, Suzuki T, Rubinstein JL. 2019. Structure of a bacterial ATP synthase. Elife 8:e43128. https://doi.org/10.7554/eLife.43128.

39. Cheng Y, Wolf E, Larvie M, Zak O, Aisen P, Grigorieff N, Harrison SC, Walz T. 2006. Single particle reconstructions of the transferrin-transferrin receptor complex obtained with different specimen preparation techniques. J Mol Biol 355:1048-1065. https://doi.org/10.1016/j.jmb.2005.11.021.

40. Dibrova DV, Konovalov KA, Perekhvatov VV, Skulachev KV, Mulkidjanian AY. 2017. COGcollator: a web server for analysis of distant relationships between homologous protein families. Biol Direct 12:29. https://doi.org/ 10.1186/s13062-017-0198-x.

41. Neuwald AF, Aravind L, Spouge JL, Koonin EV. 1999. AAA+: a class of chaperone-like ATPases associated with the assembly, operation, and disassembly of protein complexes. Genome Res 9:27-43.

42. Snider J, Thibault G, Houry WA. 2008. The AAA + superfamily of functionally diverse proteins. Genome Biol 9:216. https://doi.org/10.1186/gb-2008 $-9-4-216$.

43. Minauro-Sanmiguel F, Wilkens S, García JJ. 2005. Structure of dimeric mitochondrial ATP synthase: novel $F_{0}$ bridging features and the structural basis of mitochondrial cristae biogenesis. Proc Natl Acad Sci U S A 102:12356-12358. https://doi.org/10.1073/pnas.0503893102.

44. Allegretti M, Klusch N, Mills DJ, Vonck J, Kühlbrandt W, Davies KM. 2015. Horizontal membrane-intrinsic $\alpha$-helices in the stator a-subunit of an F-type ATP synthase. Nature 521:237-240. https://doi.org/10.1038/nature14185.

45. Blum TB, Hahn A, Meier T, Davies KM, Kühlbrandt W. 2019. Dimers of mitochondrial ATP synthase induce membrane curvature and self-assemble into rows. Proc Natl Acad Sci U S A 116:4250-4255. https://doi.org/10 .1073/pnas.1816556116.

46. Noji $H$, Ueno $H$, McMillan DGG. 2017. Catalytic robustness and torque generation of the $F_{1}$-ATPase. Biophys Rev 9:103-118. https://doi.org/10 .1007/s12551-017-0262-x. 
47. Naito TM, Masaike T, Nakane D, Sugawa M, Okada KA, Nishizaka T. 2019. Single-molecule pull-out manipulation of the shaft of the rotary motor $\mathrm{F}_{1}$ ATPase. Sci Rep 9:7451. https://doi.org/10.1038/s41598-019-43903-2.

48. Watson HC, Walker NP, Shaw PJ, Bryant TN, Wendell PL, Fothergill LA, Perkins RE, Conroy SC, Dobson MJ, Tuite MF. 1982. Sequence and structure of yeast phosphoglycerate kinase. EMBO J 1:1635-1640. https://doi .org/10.1002/j.1460-2075.1982.tb01366.x.

49. Jaffe JD, Stange-Thomann N, Smith C, DeCaprio D, Fisher S, Butler J, Calvo S, Elkins T, FitzGerald MG, Hafez N, Kodira CD, Major J, Wang S, Wilkinson J, Nicol R, Nusbaum C, Birren B, Berg HC, Church GM. 2004. The complete genome and proteome of Mycoplasma mobile. Genome Res 14:1447-1461. https://doi.org/10.1101/gr.2674004.

50. Lu M, Holliday LS, Zhang L, Dunn WA, Jr, Gluck SL. 2001. Interaction between aldolase and vacuolar $\mathrm{H}^{+}$-ATPase: evidence for direct coupling of glycolysis to the ATP-hydrolyzing proton pump. J Biol Chem 276:30407-30413. https://doi.org/10.1074/jbc.M008768200.

51. Lu M, Ammar D, Ives H, Albrecht F, Gluck SL. 2007. Physical interaction between aldolase and vacuolar $\mathrm{H}^{+}$-ATPase is essential for the assembly and activity of the proton pump. J Biol Chem 282:24495-24503. https:// doi.org/10.1074/jbc.M702598200.

52. Chan CY, Dominguez D, Parra KJ. 2016. Regulation of vacuolar $\mathrm{H}^{+}$-ATPase (V-ATPase) reassembly by glycolysis flow in 6-phosphofructo-1-kinase (PFK-1)-deficient yeast cells. J Biol Chem 291:15820-15829. https://doi .org/10.1074/jbc.M116.717488.

53. Kobayashi K, Kodera N, Kasai T, Tahara YO, Toyonaga T, Mizutani M, Fujiwara I, Ando T, Miyata M. 28 May 2021. Movements of Mycoplasma mobile gliding machinery detected by high-speed atomic force microscopy. mBio https://doi.org/10.1128/mBio.00040-21.

54. Kinosita Y, Miyata M, Nishizaka T. 2018. Linear motor driven-rotary motion of a membrane-permeabilized ghost in Mycoplasma mobile. Sci Rep 8:11513. https://doi.org/10.1038/s41598-018-29875-9.

55. Miyata M, Yamamoto H, Shimizu T, Uenoyama A, Citti C, Rosengarten R. 2000. Gliding mutants of Mycoplasma mobile: relationships between motility and cell morphology, cell adhesion and microcolony formation. Microbiology 146:1311-1320. https://doi.org/10.1099/00221287-146-6-1311.

56. Aluotto BB, Wittler RG, Williams CO, Faber JE. 1970. Standardized bacteriologic techniques for the characterization of Mycoplasma species. Int J Syst Bacteriol 20:35-58. https://doi.org/10.1099/00207713-20-1-35.
57. Kawakita Y, Kinoshita M, Furukawa Y, Tulum I, Tahara YO, Katayama E, Namba K, Miyata M. 2016. Structural study of MPN387, an essential protein for gliding motility of a human-pathogenic bacterium, Mycoplasma pneumoniae. J Bacteriol 198:2352-2359. https://doi.org/10.1128/JB.00160-16.

58. Lee C, Levin A, Branton D. 1987. Copper staining: a five-minute protein stain for sodium dodecyl sulfate-polyacrylamide gels. Anal Biochem 166:308-312. https://doi.org/10.1016/0003-2697(87)90579-3.

59. Dzandu JK, Johnson JF, Wise GE. 1988. Sodium dodecyl sulfate-gel electrophoresis: staining of polypeptides using heavy metal salts. Anal Biochem 174:157-167. https://doi.org/10.1016/0003-2697(88)90531-3.

60. Zerbetto E, Vergani L, Dabbeni-Sala F. 1997. Quantification of muscle mitochondrial oxidative phosphorylation enzymes via histochemical staining of blue native polyacrylamide gels. Electrophoresis 18:2059-2064. https://doi.org/10.1002/elps.1150181131.

61. Wittig I, Schägger H. 2005. Advantages and limitations of clear-native PAGE. Proteomics 5:4338-4346. https://doi.org/10.1002/pmic.200500081.

62. Webb MR. 1992. A continuous spectrophotometric assay for inorganic phosphate and for measuring phosphate release kinetics in biological systems. Proc Natl Acad Sci U S A 89:4884-4887. https://doi.org/10.1073/ pnas.89.11.4884.

63. Zhang K. 2016. Gctf: real-time CTF determination and correction. J Struct Biol 193:1-12. https://doi.org/10.1016/j.jsb.2015.11.003.

64. Pettersen EF, Goddard TD, Huang CC, Couch GS, Greenblatt DM, Meng EC, Ferrin TE. 2004. UCSF Chimera-a visualization system for exploratory research and analysis. J Comput Chem 25:1605-1612. https://doi.org/10 .1002/jcc.20084.

65. Ando T, Kodera N, Takai E, Maruyama D, Saito K, Toda A. 2001. A high-speed atomic force microscope for studying biological macromolecules. Proc Natl Acad Sci U S A 98:12468-12472. https://doi.org/10.1073/pnas.211400898.

66. Uchihashi T, Kodera N, Ando T. 2012. Guide to video recording of structure dynamics and dynamic processes of proteins by high-speed atomic force microscopy. Nat Protoc 7:1193-1206. https://doi.org/10.1038/nprot.2012.047.

67. Ngo KX, Kodera N, Katayama E, Ando T, Uyeda TQ. 2015. Cofilin-induced unidirectional cooperative conformational changes in actin filaments revealed by high-speed atomic force microscopy. Elife 4:e04806. https:// doi.org/10.7554/eLife.04806. 